Article

\title{
Characterization of the Light Field and Apparent Optical Properties in the Ocean Euphotic Layer Based on Hyperspectral Measurements of Irradiance Quartet
}

\author{
Linhai $\mathrm{Li}^{1}{ }^{1}$, Dariusz Stramski ${ }^{1, *}$ and Mirosław Darecki ${ }^{2}$ \\ 1 Scripps Institution of Oceanography, University of California San Diego, La Jolla, CA 92093-0238, USA; \\ li1032@ucsd.edu \\ 2 Institute of Oceanology, Polish Academy of Sciences, 81-712 Sopot, Poland; darecki@iopan.gda.pl \\ * Correspondence: dstramski@ucsd.edu; Tel.: +1-858-534-3353
}

Received: 23 February 2018; Accepted: 1 June 2018; Published: 19 December 2018

\begin{abstract}
Although the light fields and apparent optical properties (AOPs) within the ocean euphotic layer have been studied for many decades through extensive measurements and theoretical modeling, there is virtually a lack of simultaneous high spectral resolution measurements of plane and scalar downwelling and upwelling irradiances (the so-called irradiance quartet). We describe a unique dataset of hyperspectral irradiance quartet, which was acquired under a broad range of environmental conditions within the water column from the near-surface depths to about $80 \mathrm{~m}$ in the Gulf of California. This dataset enabled the characterization of a comprehensive suite of AOPs for realistic non-uniform vertical distributions of seawater inherent optical properties (IOPs) and chlorophyll- $a$ concentration $(\mathrm{Chl})$ in the common presence of inelastic radiative processes within the water column, in particular Raman scattering by water molecules and chlorophyll- $a$ fluorescence. In the blue and green spectral regions, the vertical patterns of AOPs are driven primarily by IOPs of seawater with weak or no discernible effects of inelastic processes. In the red, the light field and AOPs are strongly affected or totally dominated by inelastic processes of Raman scattering by water molecules, and additionally by chlorophyll- $a$ fluorescence within the fluorescence emission band. The strongest effects occur in the chlorophyll- $a$ fluorescence band within the chlorophyll- $a$ maximum layer, where the average cosines of the light field approach the values of uniform light field, irradiance reflectance is exceptionally high approaching 1 , and the diffuse attenuation coefficients for various irradiances are exceptionally low, including the negative values for the attenuation of upwelling plane and scalar irradiances. We established the empirical relationships describing the vertical patterns of some AOPs in the red spectral region as well as the relationships between some AOPs which can be useful in common experimental situations when only the downwelling plane irradiance measurements are available. We also demonstrated the applicability of irradiance quartet data in conjunction with Gershun's equation for estimating the absorption coefficient of seawater in the blue-green spectral region, in which the effects of inelastic processes are weak or negligible.
\end{abstract}

Keywords: oceanic light field; irradiance quartet; apparent optical properties; inelastic processes; Gershun equation; ocean euphotic zone

\section{Introduction}

The ocean epipelagic zone that extends from the surface to approximately $200 \mathrm{~m}$ depth is extremely important for ocean-atmosphere interactions with implications to climate and supporting life on Earth. Most solar radiation incident on the ocean is absorbed within this layer [1,2]. In the euphotic layer that overlaps with the upper portion or the entire epipelagic zone in very clear ocean waters, there is 
enough light to support the process of photosynthesis, which contributes nearly half of the world's total biological primary production [3]. The studies of light propagation and light field characteristics are crucial for understanding many physical and biological processes in the upper ocean, which are driven by or depend on solar radiation. For example, for studying the heating rate, the radiometric quantities of spectral downward plane irradiance, $E_{d}(z, \lambda)$, and the spectral upward plane irradiance, $E_{u}(z, \lambda)$, are essential [4]. The symbols $z$ (units of $m$ ) and $\lambda$ (units of $\mathrm{nm}$ ) stand for depth in the ocean and light wavelength in vacuum, respectively. In photosynthesis studies the key quantity of photosynthetically available radiation (PAR) is best represented on the basis of radiometric quantity of spectral scalar irradiance, $E_{0}(z, \lambda)$, and its integration over the spectral range of $350-700 \mathrm{~nm}$ or $400-700 \mathrm{~nm}$ with conversion from energy units to quantum units [5-9]. This measure of PAR is hereafter referred to as the PAR quantum scalar irradiance, $E_{O P A R}$. In the past, however, the PAR estimates in the ocean have been often based on the measurements of downward plane irradiance [10], so this measure of PAR will be referred to as PAR quantum downward irradiance, $E_{d P A R}$. The PAR estimate in terms of $E_{O P A R}$ is superior to $E_{d P A R}$, mainly because it does not ignore the contribution of upwelling light to photosynthetically available radiation and the measurement of $E_{o}$ with a spherical collector gives equal weight to quanta arriving at a point from all possible directions, in contrast to the cosine weighting in the measurement of $E_{d}$ with a plane collector. For simplicity, the explicit dependence of optical quantities on $z$ and $\lambda$ is omitted hereafter unless causing ambiguity (symbols and definitions are summarized in Table 1, see also [9] for terminology and definitions used in hydrologic optics).

Table 1. Symbols of basic variables used in this study.

\begin{tabular}{|c|c|c|}
\hline Symbol & Description & Units \\
\hline$\lambda$ & Light wavelength in vacuum & $\mathrm{nm}$ \\
\hline$z$ & Depth in water & $\mathrm{m}$ \\
\hline$\theta_{s}$ & Solar zenith angle & degree \\
\hline$a$ & Absorption coefficient & $\mathrm{m}^{-1}$ \\
\hline$b$ & Scattering coefficient & $\mathrm{m}^{-1}$ \\
\hline$c$ & Beam attenuation coefficient (sum of $a$ and $b$ ) & $\mathrm{m}^{-1}$ \\
\hline$L_{u}$ & Spectral upwelling radiance at zenith direction & $\mathrm{W} \mathrm{m} \mathrm{m}^{-2} \mathrm{sr}^{-1} \mathrm{~nm}^{-1}$ \\
\hline$E_{d}, E_{u}$ & Spectral downwelling and upwelling plane irradiances & $\mathrm{W} \mathrm{m}^{-2} \mathrm{~nm}^{-1}$ \\
\hline$E_{o}, E_{o d}, E_{o u}$ & Spectral total, downwelling, and upwelling scalar irradiances & $\mathrm{W} \mathrm{m}^{-2} \mathrm{~nm}^{-1}$ \\
\hline$K_{x}$ & Diffuse attenuation coefficients for irradiance or radiance $x$ & $\mathrm{~m}^{-1}$ \\
\hline $\bar{\mu}, \bar{\mu}_{d}, \bar{\mu}_{u}$ & Average cosines of total, down- and upwelling light fields & dimensionless \\
\hline$R$ & Irradiance reflectance & dimensionless \\
\hline Chl & Chlorophyll- $a$ concentration & $\mathrm{mg} \mathrm{m}^{-3}$ \\
\hline \multicolumn{3}{|l|}{ Subscripts } \\
\hline$w$ & Water & \\
\hline$p$ & Suspended particulate matter & \\
\hline$g$ & Colored dissolved organic matter (CDOM) & \\
\hline
\end{tabular}

Radiometric measurements in the ocean started in the early 1930s and a summary of pioneering work can be found in [11]. Example early studies include measurements of spectral irradiance, e.g., [12,13] and the angular distribution of radiance, e.g., [14-16], and determinations of some apparent optical properties (AOPs) of the ocean from light measurements, e.g., [12,17,18]. Early reports on radiometric and other optical measurements in the ocean can be also found in the Russian literature, e.g., [19].

More recent studies have considerably expanded these early measurements by using advanced instrumentation and various deployment approaches, e.g., [20-32]. Much research interest in recent decades has been concentrated on ocean reflectance in relation to applications of ocean color remote sensing. For these applications, many radiometric measurements have been collected for spectral upwelling (zenith) radiance, $L_{u}$, and $E_{d}$, and optionally also for $E_{u}$ [32-34]. Note that the zenith radiance indicates that the measured light travels toward zenith. The analysis of radiometric measurements 
driven by the interest in ocean color has been typically focused on near-surface layer, approximately the top 10-20 m. With regard to AOPs, most experimental efforts have been placed on the determinations of (i) the spectral diffuse attenuation coefficients $K_{d}, K_{u}$, and $K_{L u}$ for $E_{d}, E_{u}$, and $L_{u}$, respectively; (ii) the spectral irradiance reflectance, $R=E_{u} / E_{d}$; and (iii) the spectral remote-sensing reflectance just above the sea surface, $R_{r s}\left(z=0^{+}\right)=L_{w}\left(z=0^{+}\right) / E_{d}\left(z=0^{+}\right)$where $L_{w}$ is the spectral water-leaving radiance and $z=0^{+}$is just above the sea surface, e.g., [32,34-43]. Note also that the measurements of both $E_{d}$ and $E_{u}$ allow for determination of the net irradiance, $E=E_{d}-E_{u}$, and the diffuse attenuation coefficient for net irradiance, $K_{E}$.

In contrast to the plane irradiances $E_{d}$ and $E_{u}$, the measurements of spectral scalar irradiance, $E_{0}$, including its downward, $E_{o d}$, and upward, $E_{o u}$, components have seldom been conducted. In particular, simultaneous measurements of the irradiance quartet that includes $E_{d}, E_{u}, E_{o d}$, and $E_{o u}$ have been very rare [44] and we are unaware of explicit presentation of experimental data of the complete irradiance quartet in the literature. This greatly limits the availability of experimental data of the average cosines that provide a simple way of specifying the angular structure of the light field. The average cosines include: (i) the average cosine for the downwelling light field, $\bar{\mu}_{d}=E_{d} / E_{o d}$; (ii) the average cosine for the upwelling light field, $\bar{\mu}_{u}=E_{u} / E_{o u}$; and (iii) the average cosine for the entire light field, $\bar{\mu}=\left(E_{d}-E_{u}\right) /\left(E_{o d}+E_{o u}\right) \equiv E / E_{o}[8,9]$. We note that according to the original concept and definition of AOPs introduced by Preisendorfer $[45,46]$, the average cosines (and the reciprocal of the average cosines referred to as the distribution functions) can be considered AOPs. Preisendorfer [46] provides the following definition of AOPs: "The apparent optical properties of a natural hydrosol are those radiometrically determined scattering- and absorbing-induced quantities which generally depend on the geometrical structure of the light field (i.e., whether the light field is more or less collimated or diffuse) but which have enough regular features and enough stability to be entitled to the appellation optical property". In some studies, however, for example in the work of Kirk [10,47], the average cosines are considered just as simple parameters that specify the angular structure of the light field, and not AOPs. In this paper, we choose to refer to the average cosines as AOPs, which is consistent with the traditional view $[9,46,48]$ and simplifies the narrative structure of the presentation of our results for the three classes of parameters (i.e., $K$-coefficients, reflectances, and average cosines) which are derived from radiometric quantities. The issue of whether or not we refer to the average cosines as AOPs has no impact on the presented results.

The scarcity of simultaneous measurements of $E$ and $E_{o}$ has also greatly limited the potential use of the so-called Gershun equation [49] for estimating the absorption coefficient of seawater, $a$, from radiometric measurements or AOPs. This equation can be derived directly from the 1-D scalar (i.e., depth dependence only and no consideration of polarization of light) radiative transfer equation (RTE) for radiance, and takes a simple form $a=K_{E} \cdot \bar{\mu}$ when the inelastic radiative processes and internal sources are ignored [9]. The inelastic processes in the ocean include Raman scattering by water molecules, fluorescence by phytoplankton pigments, especially chlorophyll- $a$, and fluorescence by colored dissolved organic matter (CDOM). Few experimental studies have incorporated measurements of both spectral plane and scalar irradiances $[18,44]$ or derived the irradiance quartet from radiance measurements limited to a single or a few wavebands $[20,29,31,50]$ to examine the application of Gershun's equation. Højerslev [51] demonstrated that the irradiances involved in Gershun's equation, $E$ and $E_{o}$, can be measured with two irradiance sensors equipped with spherical collectors oriented in upward and downward looking directions and masked so that they each collect light over a hemispherical portion of the collector. This latter approach was also used by Spitzer and Wernand [52] to determine the absorption coefficient of seawater from Gershun's equation.

In principle, theoretical simulations of radiative transfer (RT) in the ocean enable the analysis of essentially all radiometric quantities of underwater light field and AOPs for various pre-defined scenarios of input data of inherent optical properties (IOPs) of seawater and boundary conditions at the sea surface and ocean bottom. There is a large body of literature in this area with a great majority of studies focusing on the so-called inverse problem or developing methods for estimating 
IOPs from radiometric measurements of natural light field or AOPs in a water body (see [53] for a review of this topic). In general, the limitations of such RT models are set by the assumptions used in their development, which include the assumptions regarding the vertical structure of IOPs and inelastic processes. The RT simulations have usually assumed a homogeneous water column and ignored all or some inelastic processes [47,54-60]. If included, the vertical stratification normally requires some idealized parameterization of the depth profile of IOPs, e.g., [60-64]. The models based on such simplifying assumptions can be satisfactory within certain limitations for the purposes of their development, for example the retrieval of average IOPs in the near-surface ocean layer. Notwithstanding the simplifying assumptions about the ocean environment, the RT modeling has provided insights into the complexity of the effects of the vertical inhomogeneity of the water column $[60,62,63,65,66]$ and inelastic processes $[60,67-75]$ on in-water and water-leaving light fields as well as AOPs. However, a comprehensive theoretical analysis of all (or nearly all) radiometric quantities (including plane and scalar irradiances) as well as the three AOP classes ( $K$-coefficients, reflectances, and average cosines) throughout the water column for a variety of complex environmental scenarios is not easily tractable, especially for various naturally-occurring vertical profiles of IOPs within the upper ocean. Such analysis has usually remained beyond the scope of RT modeling; rare examples are found in Morel and Gentili [60], which focused on the well-lit upper ocean layer, and Li et al. [64], which focused on the dimly-lit mesopelagic zone $(z>200 \mathrm{~m})$. Morel and Gentili [60] demonstrated, for example, the intricate patterns of the influences of many factors, including the sun position, seawater IOPs (as driven primarily by chlorophyll- $a$ concentration, $\mathrm{Chl}$, and co-varying water constituents), and Raman scattering, on the various AOPs within a hypothetically homogeneous ocean.

In spite of decades of experimental and theoretical studies of optical radiometry of the ocean, there exist some gaps or interesting questions, which deserve further attention. This study has been motivated by a few such questions, in particular (i) how the spectral and vertical patterns of light field characteristics and AOPs are affected by the interplay of inelastic processes (i.e., Raman scattering and chlorophyll- $a$ fluorescence) and the actual non-uniform vertical distributions of $C h l$ (and hence the vertically varying IOPs) within the euphotic layer; (ii) what relationships can be established between different AOPs using the depth-resolved data within the euphotic layer; and (iii) what is the quality and applicability of estimation of seawater absorption coefficient from measured AOPs and Gershun's equation under real conditions of non-uniform vertical distributions of Chl and IOPs, and inelastic processes within the euphotic layer. To address these questions, we collected simultaneous hyperspectral measurements of the irradiance quartet $\left(E_{d}, E_{u}, E_{o d}\right.$, and $\left.E_{o u}\right)$ and the zenith radiance $L_{u}$ from the surface to depths of $60-80 \mathrm{~m}$ in the Gulf of California. This dataset is unique because it allows conducting a case study of a comprehensive set of radiometric quantities and all essential AOPs for a broad range of specific optical and biogeochemical conditions within the water column as described by the actual vertical profiles of $C h l$ and IOPs.

\section{Methods}

\subsection{Study Area}

The field data were collected in the Gulf of California onboard the R/V New Horizon in June 2010 and June-July 2011 (Figure 1). A total of 11 stations were investigated in 2010 and 14 stations in 2011. These stations were located within three regions of the Gulf of California, Guaymas Basin, Carmen Basin, and Farallon Basin, which differ significantly in terms of water optical properties. The Guaymas Basin is the central part of the Gulf of California, Farallon Basin is the southernmost part of the Gulf of California, and Carmen Basin is located between the Guaymas and Farallon Basins. The Gulf of California has unique oceanographic and ecosystem characteristics [76,77]. According to Jerlov's optical classification of natural water bodies based on near-surface values of $K_{d}(\lambda)$ [11], the waters in the Guaymas Basin range typically between the oceanic Type IB and Type II, the Carmen Basin 
waters between the oceanic Type I and Type IA, and the Farallon Basin waters between Type II and coastal Type 1.

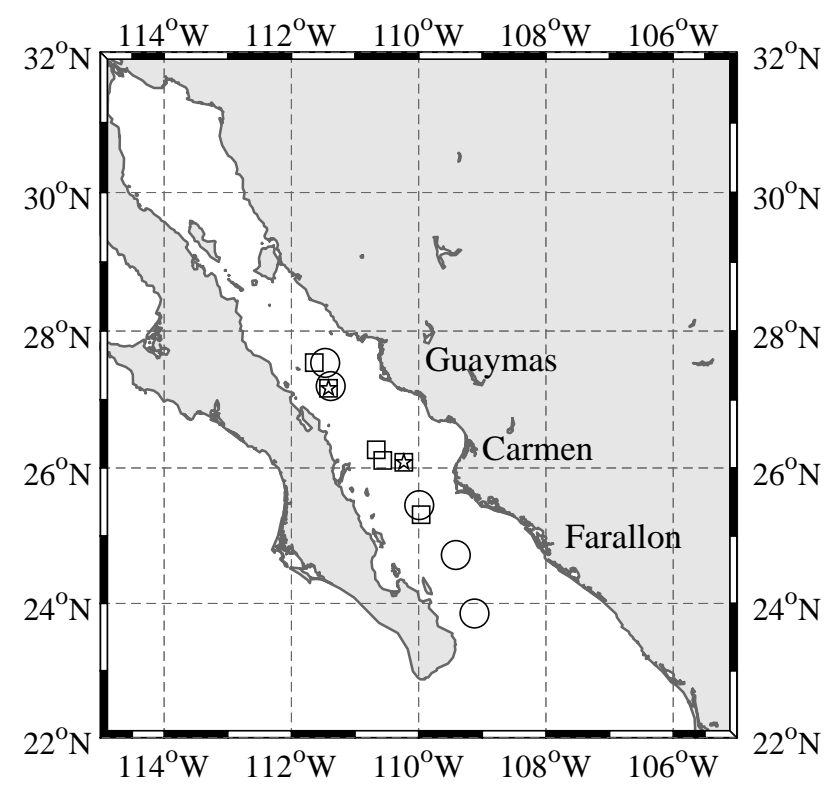

Figure 1. Location of stations in the Gulf of California where underwater radiometric and ancillary measurements were made. Circles indicate the station sites in 2010 and squares in 2011. Optical measurements were made at four, three, and four stations in the Guaymas, Carmen, and Farallon Basins, respectively. Stars indicate two stations where the absorption and beam attenuation measurements with an ac-9 instrument were made in 2011.

\subsection{CTD Measurements}

At each station, a conductivity-temperature-depth (CTD) package equipped with Niskin bottles was deployed to determine the depth profiles of seawater physical parameters (temperature $T$, salinity $S$, and density anomaly $\sigma$ ), chlorophyll- $a$ fluorescence, and non-water optical beam attenuation coefficient at $660 \mathrm{~nm}, c_{n w}(z, 660)$ (i.e., the total beam attenuation of seawater after subtraction of pure seawater contribution). Water samples were also collected at discrete depths with the CTD-Rosette for subsequent determinations of $\mathrm{Chl}$ in the laboratory.

The CTD package was deployed from water surface to $\sim 500 \mathrm{~m}$ depth. The acquired raw data were processed using a manufacturer's software, SBEDataProcessing v7.23.2 (Sea-Bird Electronics Inc., Bellevue, WA, USA), and converted to values in physical units with calibration files. The processing software automatically aligned the measurements of each sensor to the common depth vector. The calibrated data were subsequently split into down- and up-casts. Preliminary inspection of the data showed that the up-casts of CTD measurements often exhibited less noise and thus were chosen for further processing. Depth profiles of each parameter were despiked using a running median method and smoothed using a Savitzky-Golay filter in Matlab R2015b (MathWorks, Natick, MA, USA). The profiles were then binned to $0.5 \mathrm{~m}$ depth resolution to yield the final data of $T, S$, $\sigma$, chlorophyll- $a$ fluorescence, and $c_{n w}(660)$. The $c_{n w}(660)$ was considered to be equivalent to the particulate attenuation coefficient at $660 \mathrm{~nm}, c_{p}(660)$, because the absorption of dissolved material at $660 \mathrm{~nm}$ was assumed negligible.

\subsection{Chlorophyll-a Concentration}

The chlorophyll- $a$ concentration, $\mathrm{Chl}$, was determined for discrete water samples obtained from the Niskin bottles deployed during the CTD-Rosette casts. The particulate material was collected 
by filtration onto glass-fiber filters (GF/F) and stored in liquid nitrogen for post-cruise analysis. The samples collected in 2010 were analyzed with High-Performance Liquid Chromatography (HPLC) using the method described in [78]. The total Chl, which represents the summed contributions of monovinyl chlorophyll- $a$, divinyl chlorophyll- $a$, chlorophyllide- $a$, and the allomeric and epimeric forms of chlorophyll-a, was determined. In 2010, Chl was usually determined for water samples collected at two depths, 1-3 m below the sea surface and around the depth of chlorophyll- $a$ fluorescence maximum, $z_{\text {Chlmax }}$. In 2011, water samples were also collected below $z_{\text {Chlmax }}$, resulting in three water samples at each station. These samples were analyzed spectrophotometrically to determine Chl. The absorbance spectra of acetone extracts of pigments were measured inside an integrating sphere of a spectrophotometer (Perkin-Elmer Lambda 18 equipped with a 15-cm sphere) from 290 to $860 \mathrm{~nm}$ with 1-nm interval. The $\mathrm{Chl}$ concentrations were computed from absorbance values at 630, 647, 665, and $691 \mathrm{~nm}$ using the equation of Ritchie [79].

Based on Chl determinations at discrete depths, depth profiles of $C h l$ were derived by calibrating the chlorophyll- $a$ fluorescence profiles from the CTD cast. The values of fluorescence at depths of $\mathrm{Chl}$ determination were used to establish a relationship between the fluorescence signal and Chl. The squared correlation coefficient $r^{2}$ of this relationship was 0.942 and 0.938 for the data collected in 2010 and 2011, respectively. With this relationship, the depth profiles of $C h l$ were constructed using the depth profiles of measured fluorescence at all stations (see Figure 2 for an example). We note that the analysis and discussion of our results do not, however, rely strongly on exact values of Chl, but rather on relative changes in Chl.
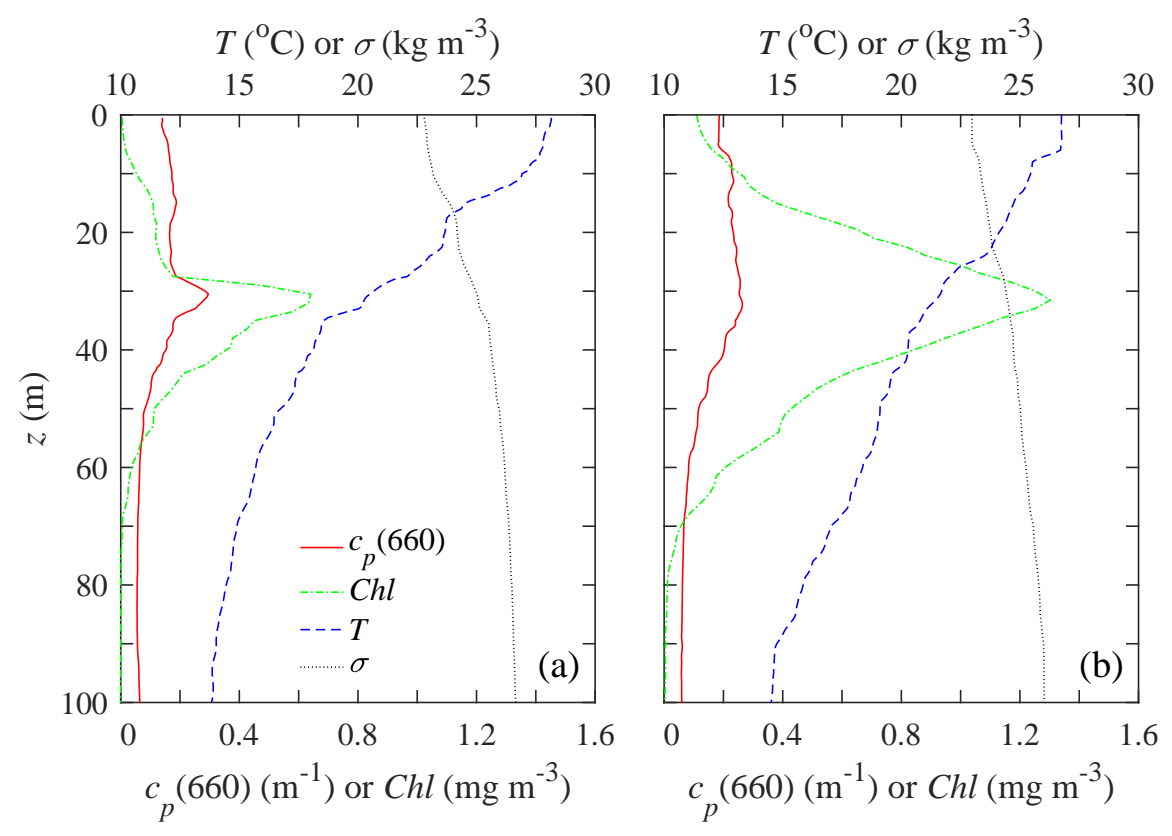

Figure 2. Vertical profiles of water temperature $T$, density anomaly $\sigma$, chlorophyll- $a$ concentration Chl, and beam attenuation coefficient of particles at $660 \mathrm{~nm} c_{p}(660)$ measured at two contrasting stations. (a) Station in the Guaymas Basin $\left(27.54^{\circ} \mathrm{N}, 111.64^{\circ} \mathrm{W}\right)$ with lower $C h l$ and $c_{p}$ and smaller solar zenith angle of $\sim 5^{\circ}$ and $(\mathbf{b})$ station in the Farallon Basin $\left(25.28^{\circ} \mathrm{N}, 109.58^{\circ} \mathrm{W}\right)$ with higher $C h l$ and $c_{p}$ and larger solar zenith angle of $\sim 57^{\circ}$.

\subsection{Radiometric Quantities and Apparent Optical Properties}

Underwater radiometric measurements, including the irradiance quartet, $E_{d}, E_{u}, E_{o d}$, and $E_{o u}$ (for all stations) and upwelling zenith radiance $L_{u}$ (for a few stations in 2011), were collected using an instrument package equipped with five RAMSES sensors (TriOS Mess- und Datentechnik GmbH, Rastede, Germany). Concurrent in-air downwelling plane irradiance, $E_{s}(\lambda)$, was also measured with an additional sensor mounted on board the ship. These sensors typically acquired signal over the 
approximate spectral range 320-950 $\mathrm{nm}$ (with slight difference among sensors) with $\sim 3.3 \mathrm{~nm}$ spectral interval across the spectrum. The radiance sensor had a $20^{\circ}$ field of view in air. All five in-water sensors were mounted on a common frame and aligned to the exact same depth level (Figure 3). The in-water package was lowered into water from the sun-exposed side of the vessel at a distance of $\sim 15 \mathrm{~m}$ from the vessel to minimize ship-induced light field perturbations [80,81]. Vertical profile measurements were taken at several discrete depths from a few meters below the surface to depths of 50 to $80 \mathrm{~m}$ depending on the station. The package was stopped and held every 3-10 $\mathrm{m}$ to acquire 5-10 spectral scans at each measurement depth. The integration time of each sensor was automatically adjusted to the light intensity at each measurement depth to ensure an adequate signal to noise ratio. The depth resolution of discrete measurements was highest near the surface and decreased to $10 \mathrm{~m}$ below the $20 \mathrm{~m}$ depth. Generally, at least one measurement was made near the depth of the Chl maximum as indicated by the chlorophyll- $a$ fluorescence profile from the CTD cast.

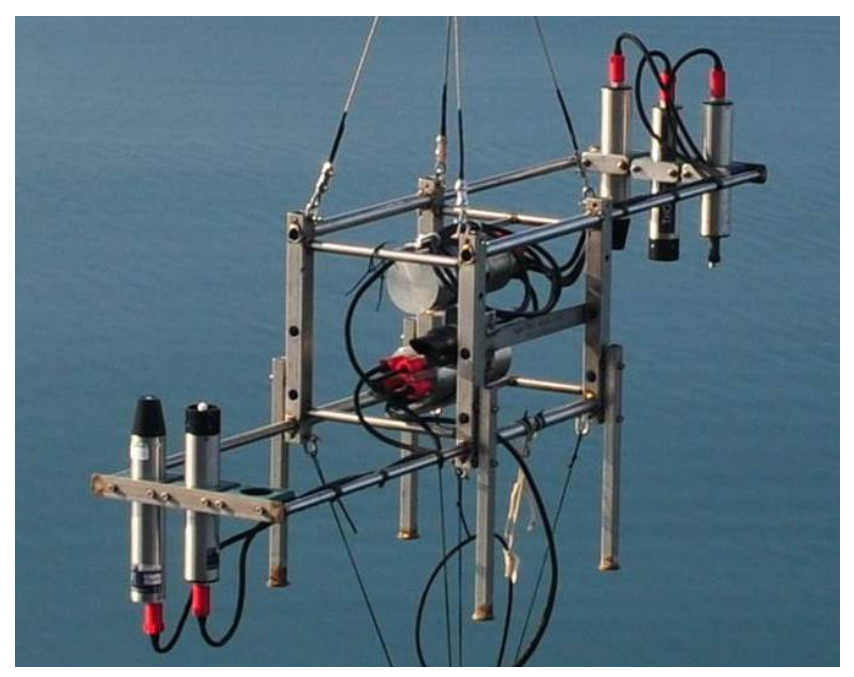

Figure 3. The instrument package used to measure the irradiance quartet and upwelling radiance. As shown, the five radiometric sensors are aligned to the same depth level.

The raw radiometric data acquired in the field were converted to physical units of spectral irradiance $\left(\mathrm{W} \mathrm{m} \mathrm{mm}^{-1}\right.$ ) and spectral radiance $\left(\mathrm{W} \mathrm{m}^{-2} \mathrm{sr}^{-1} \mathrm{~nm}^{-1}\right)$. For the underwater measurements, the correction for immersion effect was made for each sensor with the coefficients provided by the manufacturer, which were verified and revised in the laboratory experiment [82]. All measurements were matched to each other by their time stamp and assigned depth. Each spectrum was filtered using the Savitzky-Golay filter in Matlab R2015b to minimize noise, and the linear interpolation was then applied to obtain the final spectral data with a $1 \mathrm{~nm}$ spectral interval. The quality of radiometric measurements was best when the irradiance magnitude was higher than the detection limit of $10^{-6} \mathrm{~W} \mathrm{~m}^{-2} \mathrm{~nm}^{-1}$. The measurements of $L_{u}$ below $\sim 30-40 \mathrm{~m}$ were often not possible because of insufficient sensitivity of the sensor. All measurements with a signal below the detection limit were excluded from the analysis. As a result, at some stations the greatest depth of measurements of upwelling irradiance in the red spectral region was somewhat smaller (by $\sim 10-20 \mathrm{~m}$ ) compared with measurements of upwelling irradiance in the blue-green spectral region or measurements of downwelling irradiances. The underwater irradiance and radiance data that passed quality criteria were adjusted to eliminate the effects of temporal changes in sky conditions during vertical profiling with the underwater system. This was accomplished by appropriate normalization of underwater data acquired at different depths using simultaneously acquired data of $E_{s}$.

The data of irradiance quartet were used to derive a comprehensive set of AOPs at each discrete depth, including, $\bar{\mu}_{d}, \bar{\mu}_{u}, \bar{\mu}, R$ (all dimensionless), and various diffuse attenuation coefficients, 
collectively denoted with a symbol $K\left(\right.$ units of $\left.\mathrm{m}^{-1}\right)$. The $K$ coefficients for various irradiances were derived from

$$
K_{x}\left(z_{1}+\Delta z, \lambda\right)=-\frac{\ln E_{x}\left(z_{2}, \lambda\right)-\ln E_{x}\left(z_{1}, \lambda\right)}{z_{2}-z_{1}},
$$

where $x$ represents $d, u, o d$, and $o u, z_{1}$ is a depth corresponding to the upper boundary of the layer over which $K_{x}$ is determined, $z_{2}$ is the lower boundary of this layer, and $\Delta z=\left(z_{2}-z_{1}\right) / 2$. Similarly, other $K_{x}$ coefficients were also calculated, specifically the diffuse attenuation coefficient of net irradiance, $K_{E}$, by replacing $E_{x}$ with net irradiance, $E=E_{d}-E_{u}$, and the diffuse attenuation coefficient of upwelling zenith radiance, $K_{L u}$, by replacing $E_{x}$ with $L_{u}$. PAR quantum scalar irradiance, $E_{O P A R}$ (in units of $\mu \mathrm{mol}$ quanta $\mathrm{m}^{-2} \mathrm{~s}^{-1}$ ), was calculated by the conversion of spectral $E_{0}$ from energy units to quantum units and integration between 400 and $700 \mathrm{~nm}$. Similarly, PAR quantum downward irradiance, $E_{d P A R}$, was calculated from spectral $E_{d}$. The corresponding diffuse attenuation coefficients, $K_{O P A R}$ and $K_{d P A R}$, were calculated by replacing $E_{x}$ with $E_{O P A R}$ and $E_{d P A R}$, respectively, in Equation (1).

The spectra of all AOPs were inspected to ensure the quality of data. Because at each depth multiple radiometric measurements were taken, AOPs were initially determined from each radiometric measurement. The unrealistic AOPs, for example $R>1$ or average cosines $>1$, or obvious outliers were then discarded. The abnormal data were often observed near the surface, most likely owing to the effects of wave-induced light fluctuations in $E_{d}$ and $E_{o d}[83,84]$. After this quality control, the accepted spectra of radiometric quantities were averaged to generate final data of irradiances and radiance for each depth of measurement. The average spectra of irradiances and radiance were then used to compute the final AOPs. Such final data from 11 stations (five in 2010 and six in 2011; see Figure 1) that included valid measurements at more than four depths were selected for further analysis in this study.

\subsection{Absorption and Beam Attenuation Coefficients}

The non-water absorption coefficient, $a_{n w}(z, \lambda)=a(z, \lambda)-a_{w}(\lambda)$, and non-water beam attenuation coefficient, $c_{n w}(z, \lambda)=c(z, \lambda)-c_{w}(\lambda)$, were measured at five stations in 2011 with an ac-9 instrument equipped with nine spectral bands; 412, 440, 488, 510, 532, 555, 650, 676, and $715 \mathrm{~nm}$ (WET Labs, Inc., Philomath, OR, USA). $a(z, \lambda)$ and $c(z, \lambda)$ are the total absorption and beam attenuation coefficients of seawater and $a_{w}(\lambda)$ and $c_{w}(\lambda)$ represent the pure seawater contributions to these coefficients, respectively. Note that $a_{n w}(z, \lambda)$ is often written as a sum of $a_{p}(z, \lambda)$ and $a_{g}(z, \lambda)$ where the subscripts $p$ and $g$ represent the contributions associated with suspended particulate matter and CDOM, respectively. The coefficient $c_{n w}(z, \lambda)$ can be written as a sum of $a_{n w}(z, \lambda)$ and $b_{p}(z, \lambda)$, where $b_{p}(z, \lambda)$ represents the particulate component of the total scattering coefficient of seawater, $b(z, \lambda)$.

Vertical profiles of ac-9 data were obtained from the surface to $\sim 500 \mathrm{~m}$ depth. The first step of data processing included quality checking of downcast and upcast measurements and rejecting doubtful and excessively noisy data. Because data were often missing for the upcast profiles within the top $\sim 30-50 \mathrm{~m}$ layer, only the downcast data were used for further processing, which included temperature and salinity correction [85], subtraction of a baseline determined with Milli-Q water before the cruise, and binning to $0.5 \mathrm{~m}$ depth resolution. The $a_{n w}(z, \lambda)$ values were additionally corrected for the scattering error by subtracting the values at $715 \mathrm{~nm}$ at all ac-9 wavelengths. After quality control, only two stations (indicated in Figure 1) provided ac-9 data with concurrent radiometric measurements described in Section 2.4 .

\subsection{Regression Analysis}

The presented results of regression analysis are mostly based on the Model I regression method because our objective was to formulate a functional relationship for estimating the ordinate variable $y$ from the abscissa variable $x$ [86]. The ordinary least squares method was applied for all linear relationships and the nonlinear least squares method was applied to all non-linear relationships. The regression calculations were performed using standard fitting methods in Matlab R2015b. 
The ordinary (untransformed) variables $x$ and $y$ were used as input to the fitting procedure. The fitting process in Matlab R2015b also outputs root mean squared error, RSME, that is calculated as:

$$
R M S E=\sqrt{\frac{\sum_{i=1}^{N}\left(y_{i}-x_{i}\right)^{2}}{N-m}},
$$

where $N$ is the total number of data points and $m$ is the number of coefficients fitted via the regression analysis.

In one case of our data analysis, we applied the Model II regression method in which the relationship was estimated using the slope of major (principal) axis of the bivariate dataset (Section 3.3). In this specific analysis we compared the estimates of the absorption coefficient obtained with two different experimental methods based on irradiance quartet and ac-9 measurements.

\section{Results and Discussion}

\subsection{Contrasting Examples of Light Field Characteristics and AOPs}

Our measurements show that the bio-optical properties within the Gulf of California exhibited a large range of variability, which is summarized in terms of $C h l$ and $c_{p}(660)$ data in Table 2. The examined water column extended from the surface to a maximum measurement depth of $80 \mathrm{~m}$. The depth of euphotic layer, $z_{e u}$, was determined using a conventional criterion by estimating a depth at which the surface PAR (i.e., $E_{O P A R}$ ) was reduced to $1 \%$. The depth $z_{e u}$ ranged from about 30 to $60 \mathrm{~m}$ depending on time and location of measurement. Typically, our measurements (at least in the blue-green spectral region) extended $\sim 10-30 \mathrm{~m}$ below $z_{e u}$, and these maximum measurement depths corresponded to $\sim 0.1-0.5 \%$ of surface $E_{O P A R}$. Because phytoplankton have specific energetic demand rather than demand for percentage of light, it is reasonable to expect that the compensation depth of phytoplankton photosynthesis for specific latitude, season, and optical water types investigated in our study was greater than $z_{e u}$, probably closer to $0.1 \%$ of surface PAR [87]. Therefore, we refer to the entire investigated water column as the euphotic layer.

Table 2. Summary of data characterizing the shallowest and greatest depths of radiometric measurements, the depth of chlorophyll- $a$ maximum, and the corresponding chlorophyll- $a$ concentration, $C h l$, and particulate beam attenuation coefficient at $660 \mathrm{~nm}, c_{p}(660)$, for these depths based on all stations during the 2010 and 2011 cruises in the Gulf of California. For each of these variables the average value \pm standard deviation with the minimum and maximum values in parenthesis are given. In addition, the minimum and maximum values of the solar zenith angle $\theta_{s}$ and the data characterizing the euphotic depth $z_{e u}$ (the average value \pm standard deviation with the minimum and maximum values in parenthesis) are shown for all stations.

\begin{tabular}{cccc}
\hline Depth of Measurement & Shallowest & Greatest & Chl Maximum \\
\hline$z(\mathrm{~m})$ & $5.4 \pm 2.9$ & $64.9 \pm 12.1$ & $33.0 \pm 9.9$ \\
& $(1.2,10.5)$ & $(47.6,80.7)$ & $(20.4,50.5)$ \\
\hline \multirow{2}{*}{$C h l\left(\mathrm{mg} \mathrm{m}^{-3}\right)$} & $0.067 \pm 0.067$ & $0.13 \pm 0.15$ & $0.81 \pm 0.54$ \\
& $(0.005,0.24)$ & $(0.004,0.42)$ & $(0.25,2.17)$ \\
\hline \multirow{2}{*}{$c_{p}(660)\left(\mathrm{m}^{-1}\right)$} & $0.173 \pm 0.035$ & $0.089 \pm 0.048$ & $0.239 \pm 0.076$ \\
& $(0.103,0.238)$ & $(0.043,0.202)$ & $(0.125,0.405)$ \\
\hline Solar zenith angle $\theta_{s}($ degrees $)$ & $0.5-57.1$ & & \\
\hline \multirow{2}{*}{ Euphotic depth $z_{\text {eu }}(\mathrm{m})$} & $40.5 \pm 8.9$ & & \\
\hline
\end{tabular}


Within the examined water column, Chl varied from extremely low levels on the order of $10^{-3}$ to more than $2 \mathrm{mg} \mathrm{m}^{-3}$ with the highest values observed within the Chl maximum $\left(\mathrm{Chl}_{\max }\right)$ layer and the lowest values either near the surface or at the deepest measurement depths $(\sim 60-80 \mathrm{~m})$. The shape of the $\operatorname{Chl}(z)$ vertical profile also changed significantly within the study area. The depth $z_{\text {Chlmax }}$ of $C h l_{\max }$ ranged from about $20 \mathrm{~m}$ to $50 \mathrm{~m}$. The full width half maximum (FWHM) of the Chl max layer, when fitted to a Gaussian function, ranged from $5 \mathrm{~m}$ to $30 \mathrm{~m}$. Significant variations spanning one order of magnitude from about 0.04 to $0.4 \mathrm{~m}^{-1}$ were also observed in $c_{p}(z, 660)$. In addition, our measurements were conducted under a broad range of the solar zenith angle, $\theta_{s}$, varying between $0.5^{\circ}$ (i.e., the sun nearly at zenith) to $57.1^{\circ}$. Such broad range of environmental conditions is evident in terms of diverse scenarios in the measured light field characteristics and AOPs.

In this section we discuss two contrasting scenarios of light fields and AOPs within the euphotic layer, one was located in the Guaymas Basin which was observed in 2011 (Figure 2a) and the other in the Farallon Basin which was observed in 2010 (Figure 2b). Figure 2 compares the vertical profiles of $T, \sigma, C h l$, and $c_{p}(660)$ at both stations. These two stations have highly contrasting Chl profiles and also exhibit noticeable differences in the $c_{p}(660)$ profiles. Although both stations had a similar depth of $C h l_{\max }(\sim 30 \mathrm{~m})$ the magnitude and FWHM of the $C h l_{\max }$ layer were very different. Specifically, the magnitude of $C h l_{\max }$ in the Farallon Basin $\left(1.3 \mathrm{mg} \mathrm{m}^{-3}\right)$ was about twice as high as compared with that observed in the Guaymas Basin $\left(0.64 \mathrm{mg} \mathrm{m}^{-3}\right)$. The FWHM was also considerably larger in the Farallon Basin, i.e., $25 \mathrm{~m}$ vs. $10 \mathrm{~m}$ in the Guaymas Basin. In general, the magnitudes of $c_{p}(660)$ for these two stations did not differ significantly but the vertical distributions were different. In particular, there was a noticeable local maximum of $c_{p}(660)$ near the depth of $C h l_{\max }$ in the Guaymas Basin, and no similar feature was observed in the Farallon Basin. The observed optical differences between the stations could have been caused by differences in the characteristics of suspended particulate matter such as organic and mineral composition. In addition, whereas the measurements were made under clear skies, the solar zenith angle was dramatically different at these two stations, $5.5^{\circ}$ in the Guaymas Basin (the measurement was taken around noon at 12:45 p.m. local time) and $57.1^{\circ}$ in the Farallon Basin (the measurement taken late afternoon at 4:35 p.m.). Thus, the comparison of these two stations provides an illustration of differences in the light field and AOPs, which were affected not only by water optical properties but also solar zenith angle. We will first present the data of irradiance quartet (Figure 4) and AOPs (Figures 5 and 6) for the station in the Guaymas Basin, and then the AOPs for the station in the Farallon Basin (Figure 7).

The spectra of irradiances, $E_{d}, E_{u}, E_{o d}$, and $E_{o u}$, at several discrete depths within the top $70 \mathrm{~m}$ of the water column are presented in Figure $4 a-d$. These results illustrate the well-known general pattern of the vertical change in the irradiance spectra in the upper ocean, including a decrease in the magnitude and narrowing of the spectral distribution with an increase in depth, e.g., [11]. In the investigated waters, all four irradiances exhibited well-pronounced maximum at a wavelength of about $495 \mathrm{~nm}$ at the deepest measurement depth of $67 \mathrm{~m}$, but the spectral distributions of downwelling light, $E_{d}$ and $E_{o d}$, were clearly broader with relatively more light in the green compared with the distributions for the upwelling light, $E_{u}$ and $E_{o u}$. A remarkable feature associated with vertically non-uniform fluorescence of chlorophyll- $a$ was also evident in the irradiance spectra. At a depth of $29 \mathrm{~m}$ that coincides with $z_{\text {Chlmax }}$ the spectra of $E_{d}$ and $E_{o d}$ showed a distinct maximum in the spectral band of maximum fluorescence centered around $683 \mathrm{~nm}$. This maximum was even more pronounced in the spectra of $E_{u}$ and $E_{o u}$. This feature weakened greatly for $E_{d}$ and $E_{o d}$ at depths shallower or deeper than $z_{\text {Chlmax }}$, but was preserved in the spectra of $E_{u}$ and $E_{o u}$ throughout the water column, which was expected as long as Chl did not drop to a very low level. 

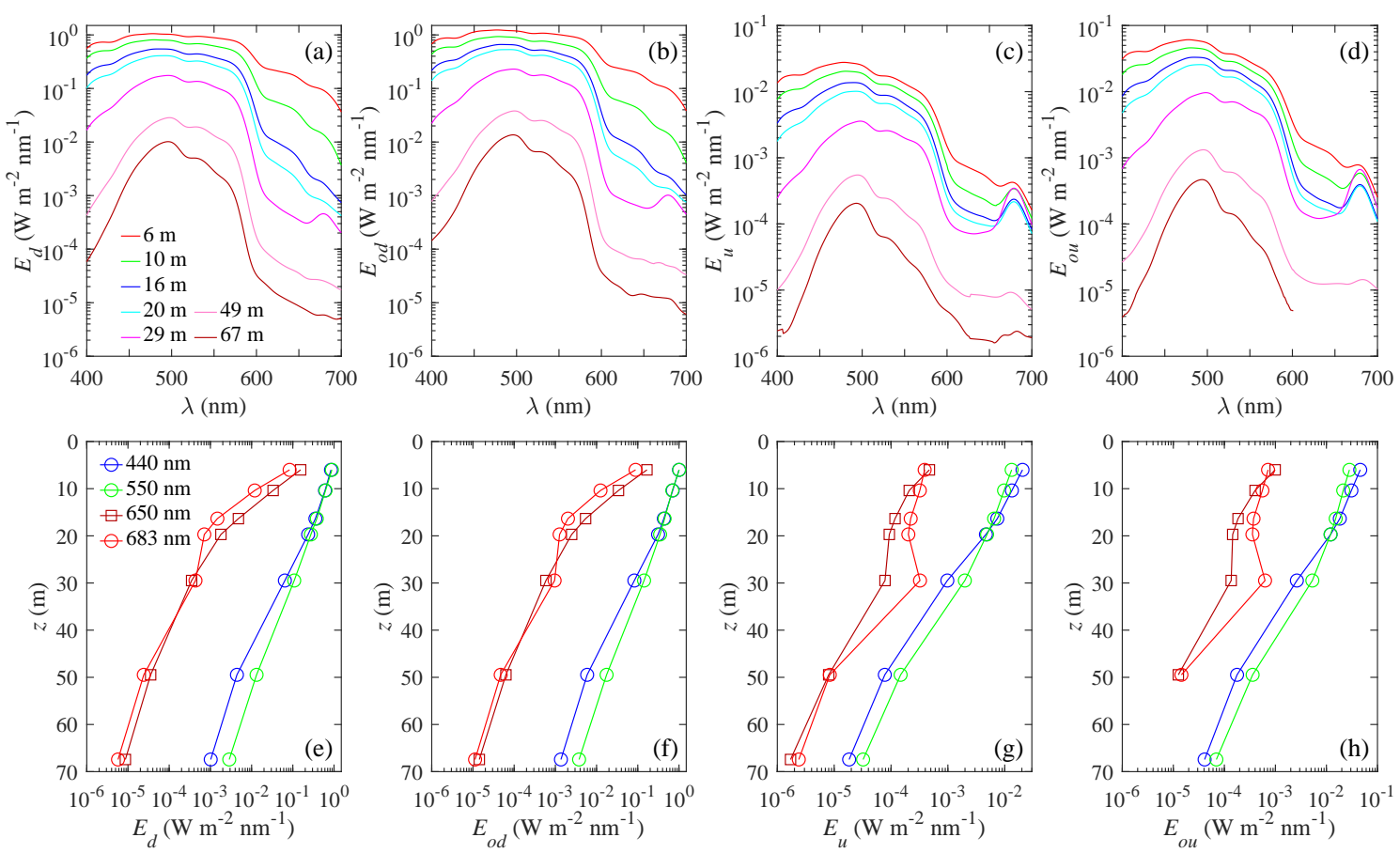

Figure 4. Spectra and vertical profiles of the irradiance quartet, $E_{d}(\mathbf{a}, \mathbf{e}), E_{o d}(\mathbf{b}, \mathbf{f}), E_{u}(\mathbf{c}, \mathbf{g})$, and $E_{o u}$ $(\mathbf{d}, \mathbf{h})$, measured at the station in the Guaymas Basin shown in Figure 2a. In panels $(\mathbf{a}-\mathbf{d})$ different colors represent the measurement depths as indicated in (a). In (e-h) different colors and symbols represent selected light wavelengths as indicated in (e).
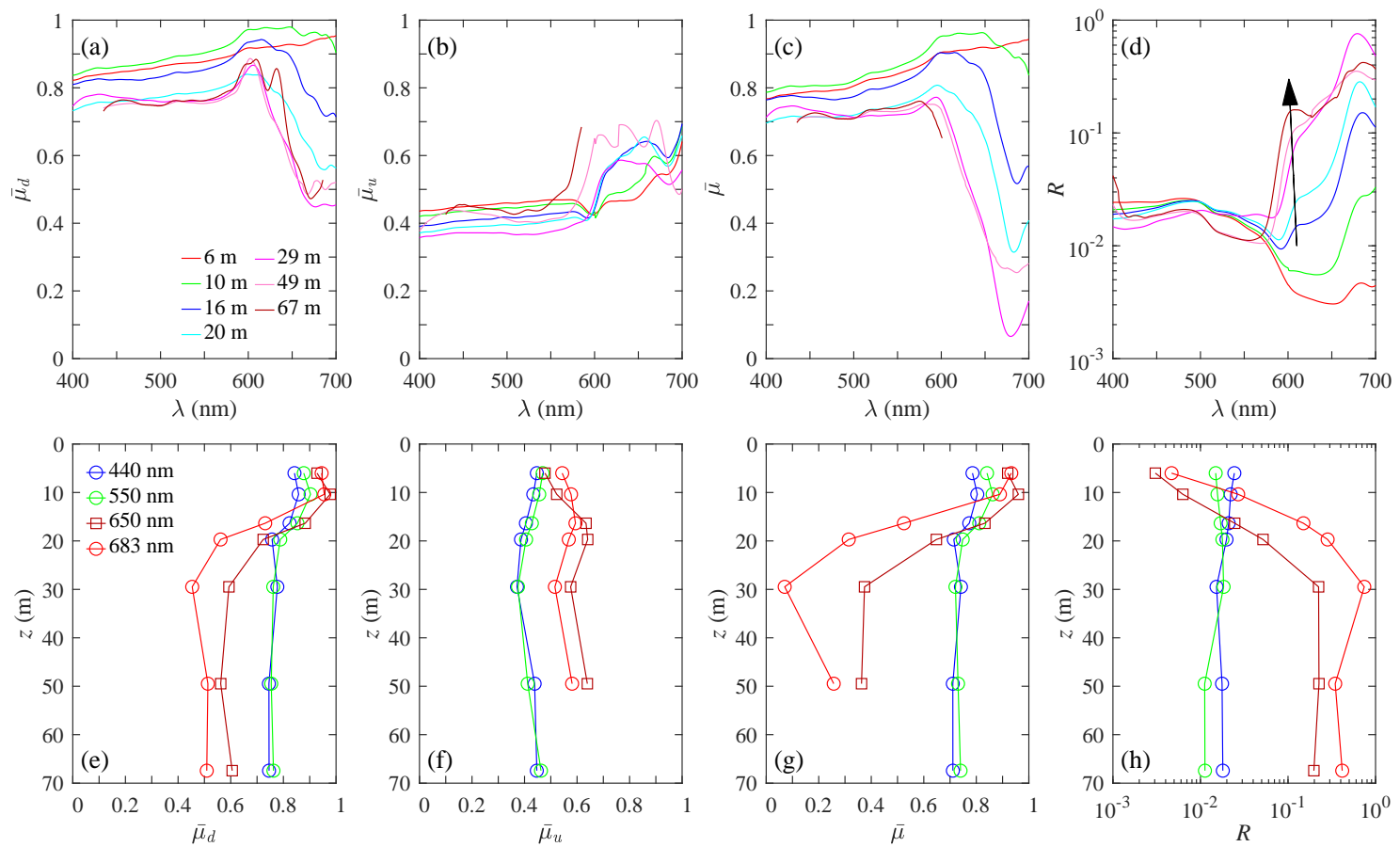

Figure 5. Spectra and vertical profiles of average cosines of underwater light field, $\bar{\mu}_{d}(\mathbf{a}, \mathbf{e}), \bar{\mu}_{u}(\mathbf{b}, \mathbf{f})$ and $\bar{\mu}(\mathbf{c}, \mathbf{g})$ as well as irradiance reflectance, $R(\mathbf{d}, \mathbf{h})$, derived from the irradiance quartet for Guaymas Basin shown in Figure 4. In panels (a-d) different colors represent depths as indicated in (a). The black arrow in (d) indicates a spectral feature caused by Raman scattering of water molecules. In (e-h) different colors and symbols represent light wavelengths as indicated in (e). 

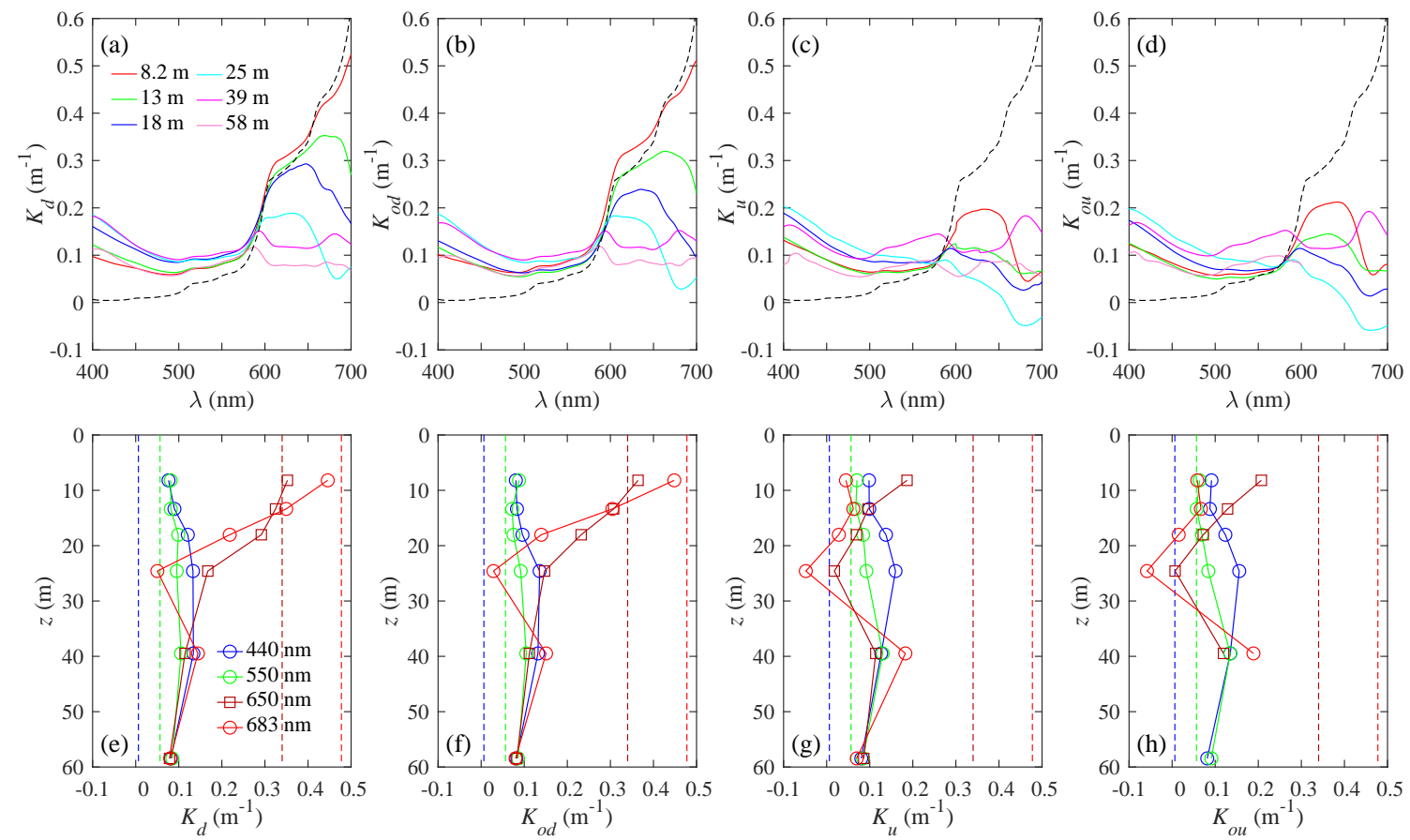

Figure 6. Spectra and vertical profiles of diffuse attenuation coefficients, $K_{d}(\mathbf{a}, \mathbf{e}), K_{o d}(\mathbf{b}, \mathbf{f}), K_{u}(\mathbf{c}, \mathbf{g})$, and $K_{o u}(\mathbf{d}, \mathbf{h})$, derived from the irradiance quartet for Guaymas Basin in Figure 4. In panels (a-d) different colors represent the mid-point depths of the layers within which the $K$ coefficients were determined as indicated in panel (a). Dashed lines represent the spectrum of pure water absorption coefficient, which is a theoretical minimum of $K$ for a hypothetical case when no inelastic processes and true emission sources are present. In (e-h) different colors and symbols represent the light wavelengths as indicated in panel (e) and dashed lines represent pure water absorption at respective wavelengths.
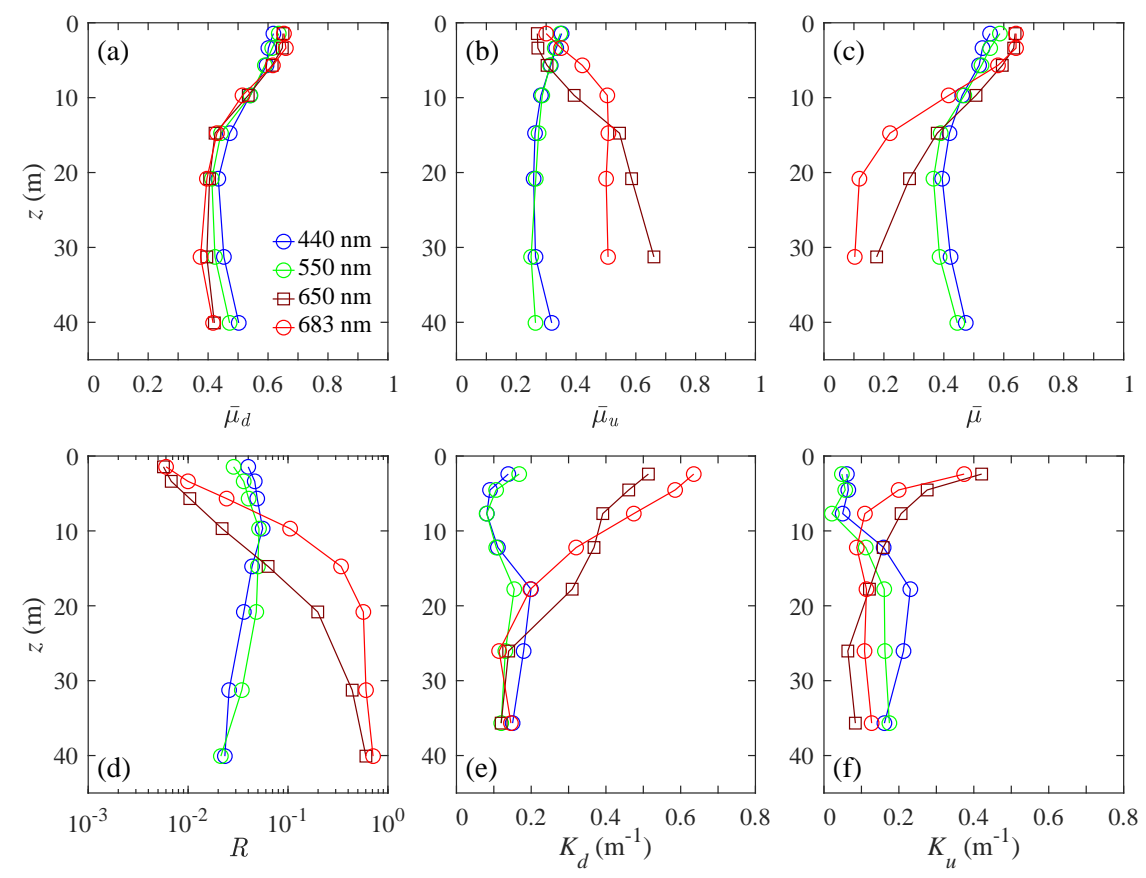

Figure 7. Vertical profiles of average cosines, irradiance reflectance, and diffuse attenuation coefficients for the station in the Farallon Basin shown in Figure $2 \mathrm{~b}$. Data for $\bar{\mu}_{d}$ panel (a); $\bar{\mu}_{u}(\mathbf{b}) ; \bar{\mu}(\mathbf{c}) ; R(\mathbf{d}) ; K_{d}(\mathbf{e}) ;$ and $K_{u}(\mathbf{f})$ are shown for selected light wavelengths as indicated in panel (a). 
The effects of vertically non-uniform IOPs and chlorophyll- $a$ fluorescence were also clearly revealed in the depth profiles of the irradiance quartet at four selected wavelengths (Figure $4 \mathrm{e}-\mathrm{h}$ ). Because the unscattered and elastically scattered light in the red spectral region was efficiently removed within the near-surface layer owing to strong absorption by water molecules, the vertical profiles in the red (650 and $683 \mathrm{~nm}$ ) were affected by inelastic processes (Raman scattering and chlorophyll- $a$ fluorescence) to much greater extent compared with shorter wavelengths, and hence differed significantly from the profiles in the blue and green $(440$ and $550 \mathrm{~nm})$. The slope of the profiles in the blue and green showed relatively small variations with depth, which were driven primarily by vertical inhomogeneity in IOPs associated with the strength of absorption and elastic scattering processes. For example, at $440 \mathrm{~nm}$ all four irradiances showed steeper profiles (i.e., higher attenuation rate with depth) within the $C h l_{\text {max }}$ layer, which can be attributed largely to enhanced absorption of blue light by phytoplankton. In contrast, the slope of irradiance profiles in the red varied within the water column to much greater extent compared with shorter wavelengths. For example, in the $650 \mathrm{~nm}$ band the profiles of $E_{d}$ and $E_{o d}$ became gradually less steep with depth, which can be attributed largely to the increasing contribution of Raman scattering. In the $683 \mathrm{~nm}$ band where the contribution of chlorophyll- $a$ fluorescence was strongest, $E_{d}$ and $E_{o d}$ remained nearly constant with increasing depth within the upper portion of the $C h l_{\max }$ layer (note that no data is available to resolve the depth variations throughout the lower portion of the $C h l_{\max }$ layer as the next data point at $50 \mathrm{~m}$ was near the base of the $C h l_{\max }$ layer). The effects of inelastic processes were, however, most pronounced for $E_{u}$ and $E_{o u}$ in the red spectral region. At $683 \mathrm{~nm}$ the effect of chlorophyll- $a$ fluorescence on the upwelling light field was so strong that both $E_{u}$ and $E_{o u}$ increased with depth within the upper portion of the $C h l_{\max }$ layer. Although Raman scattering is known to have very important contribution to the upwelling light in the red $[9,60,64,71,88]$, our data show that the fluorescence effect in the $683 \mathrm{~nm}$ band can be dominant in the presence of $C h l_{\max }$ layer. At $650 \mathrm{~nm} E_{u}$ and $E_{o u}$ remain nearly constant within the upper portion of the $C h l_{\max }$ layer. This suggests that the fluorescence fingerprint in the upwelling irradiances is still noticeable at this wavelength, which can be attributed to relatively broad emission band of chlorophyll-a fluorescence (FWHM of $\sim 20-25 \mathrm{~nm}$ ) [89,90].

The vertical variations in the spectral AOPs derived from the irradiance quartet measurements reveal features that were clearly associated with the effects of inelastic processes in the presence of non-uniform profiles of $\mathrm{Chl}$ and IOPs (Figures 5 and 6). The spectra and depth profiles of the average cosines, $\bar{\mu}_{d}, \bar{\mu}_{u}$, and $\bar{\mu}$, were relatively weakly variable within the blue-green spectral region where the effects of inelastic processes are much weaker compared with the long-wavelength portion of the spectrum (Figure $5 \mathrm{a}-\mathrm{c}, \mathrm{e}-\mathrm{g}$ ). In the spectral range of $400-580 \mathrm{~nm}$, the values of $\bar{\mu}_{d}$ and $\bar{\mu}$ were in the range $0.7-0.9$ with higher values observed at shallower depths and related to the high solar elevation in the clear sky during the measurement. Thus, the downwelling light field or the entire light field was characterized by the predominant downward direction of light propagation within $45^{\circ}$ of the vertical. The values of $\bar{\mu}_{u}$ in the blue-green were around 0.4 suggesting more uniform angular distribution of upwelling light field. Our data of average cosines in the blue-green are in the range of theoretical and experimental values reported in other studies $[9,10,29,52,60,73]$. In the red spectral region, the average cosines exhibited large variations owing to the effects of inelastic processes within the non-uniform water column. We observed a large rapid decrease in $\bar{\mu}_{d}$ and $\bar{\mu}$ below the near-surface layer (below $10 \mathrm{~m}$ ) to about 0.5 and 0.05 , respectively, at depths $\geq 20 \mathrm{~m}$. For $\bar{\mu}_{u}$ in the red we observed a variation between about 0.45 and 0.65 . The observed values of average cosines in the red differ significantly from those which would have occurred if inelastic processes were absent [9,73]. In the presence of inelastic processes, the light field in the red approached a more uniform distribution with increasing depth quite rapidly, and could achieve a nearly isotropic distribution within moderately strong $C h l_{\max }$ layer at relatively shallow depths, such as $\sim 30 \mathrm{~m}$ in the examined case (Figure $5 \mathrm{e}-\mathrm{g}$ ). Note also that, unlike Raman scattering that leads gradually to a more uniform light field in the red with increasing depth, the vertically non-uniform chlorophyll- $a$ fluorescence caused additional depth variations in the angular distribution of light field within the $683 \mathrm{~nm}$ band. In contrast, in the blue-green region 
where the effects of inelastic processes are much weaker, the light field remained highly directional throughout the examined euphotic layer (Figure 5e-g).

Similar to the average cosines, the spectral irradiance reflectance $R$ (Figure $5 \mathrm{~d}$,h) showed relatively little variation with depth in the blue-green spectral region as the $R$ values ranged between 0.01 and 0.025 . In contrast, $R$ exhibited very large vertical variations at wavelengths longer than about $580 \mathrm{~nm}$. In the red $R$ varied from about 0.003 at $6 \mathrm{~m}$ to 0.8 at $z_{\text {Chlmax }}=29 \mathrm{~m}$, and relatively high values (0.2-0.4) persisted below the $\mathrm{Ch} l_{\max }$ layer (Figure $5 \mathrm{~h}$ ). Similar observations were previously reported by Dirks and Spitzer [37]. This result was caused by inelastic processes, including a dominant effect of chlorophyll- $a$ fluorescence that produces a maximum in the $R$ spectra within the fluorescence emission band centered at $683 \mathrm{~nm}$ (Figure 5d). At shorter wavelengths within the approximate range 580-650 nm that was away from significant effect of chlorophyll- $a$ fluorescence, Raman scattering appeared to exert a dominant influence on $R$ throughout much of the examined water column. Owing to this inelastic process a shoulder-like feature was seen in the $R$ spectra around $600 \mathrm{~nm}$ at intermediate measurement depths (16-49 m), which developed into a distinct maximum with further increase of depth to $67 \mathrm{~m}$ (Figure $5 \mathrm{~d}$ ). This pattern is consistent with an increasing role of Raman scattering with depth $[37,69,70,73]$. These results also suggest that the effects of Raman scattering were more easily detectable or distinguishable from the effects of chlorophyll- $a$ fluorescence in the data of AOPs than in the irradiance data.

Figure 6 shows the attenuation coefficients for the four irradiances, specifically $K_{d}, K_{u}, K_{o d}$, and $K_{o u}$, as derived from the measurements of irradiance quartet, $E_{d}, E_{u}, E_{o d}$, and $E_{o u}$, respectively. Similar to other AOPs discussed above, the $K$-coefficients were less variable in the blue-green than in the red portion of the spectrum, both in terms of the spectral shape (Figure 6a-d) and vertical profiles (Figure 6e-h). One of the most remarkable features was that the $K$-coefficients in the red (more specifically for $\lambda>580-600 \mathrm{~nm}$ ) were generally smaller than the pure water absorption coefficient, $a_{w}$. This feature resulted from inelastic processes and was more pronounced for $K_{u}$ and $K_{o u}$ than $K_{d}$ and $K_{o d}$. In the chlorophyll- $a$ fluorescence band, $K_{d}$ and $K_{o d}$ approached zero in the upper portion of the Chl max layer (Figure 6e,f), which is consistent with an earlier observation that $E_{d}$ and $E_{o d}$ are nearly constant within that layer (Figure 4e,g). A stronger effect within the $683 \mathrm{~nm}$ band was observed for the $K_{u}$ and $K_{o u}$ coefficients that assume negative values in the upper portion of the $C h l_{\max }$ layer (Figure $6 \mathrm{~g}, \mathrm{~h}$ ). This is again consistent with the measurements of $E_{u}$ and $E_{o u}$ which both increased with depth within that layer (Figure 4f,h). Similar increase of $E_{u}$ in the red band ( $685 \mathrm{~nm}$ ) with depth within the $C h l_{\max }$ layer was previously observed by Dirks and Spitzer [37]. The presence of negative values for the attenuation of upwelling irradiance was also demonstrated through RT simulations of light field within highly scattering near-surface layer of bubble clouds entrained by wave breaking [91]. Other interesting features of the long-wavelength portion of $K$-spectra include a maximum at $683 \mathrm{~nm}$ below $z_{\text {Chlmax }}$ (for all $K$-coefficients, see Figure $6 \mathrm{a}-\mathrm{d}$ ) or a maximum that could peak at wavelengths longer than about $600 \mathrm{~nm}$ but shorter than $683 \mathrm{~nm}$ at depths above $z_{\text {Chlmax }}$ (especially for $K_{d}$ and $K_{o d}$, see Figure $\left.6 a, b\right)$. These features arise from differential spectral effects of inelastic processes as a function of increasing wavelength. It is also interesting to note that a distinct feature at these intermediate depths was observed in the spectra of $\bar{\mu}_{d}$ and $\bar{\mu}$ (Figure $5 \mathrm{~b}, \mathrm{~d}$ ). This can be explained by higher attenuation coefficient leading to more light concentrated around the vertical direction.

In contrast to the red portion of the spectrum, in the blue-green spectral region where the effects of inelastic processes are much weaker, the $K$-coefficients were higher than $a_{w}(\lambda)$. At these wavelengths, especially at $440 \mathrm{~nm}$, the vertical profiles of $K$-coefficients exhibited maximum values within the $C h l_{\text {max }}$ layer, and hence generally resembled the shape of $\operatorname{Chl}(z)$ profile. It is also noteworthy that the $K$-coefficients at all different wavelengths became nearly identical at the greatest depth of about $60 \mathrm{~m}$ used in these determinations (Figure 6e-h). This was primarily because the effect of Raman scattering generally led to a gradual decrease of $K$-coefficients in the red, for example at $650 \mathrm{~nm}$, with increasing depth until approaching the level of $K$-coefficients in the blue and green. This pattern that eventually led to relatively flat $K$-coefficients has been demonstrated previously in experimental 
data and theoretical results from RT simulations [37,64,73]. It is, however, important to emphasize that we do not suggest that the light field in the examined case has reached an asymptotic regime within the deepest portion of the examined layer (i.e., $\sim 60-70 \mathrm{~m}$ ) where we observe such similarity of $K$-coefficients and relatively constant AOPs with depth. While such patterns can be associated with the asymptotic regime, previous deep-sea RT simulations demonstrated that a nearly asymptotic light field could generally be reached only at significantly greater depths within the ocean mesopelagic zone [64,73].

For comparison with the results discussed above in the Guaymas Basin, Figure 7 shows the vertical profiles of AOPs obtained from measurements at a station in the Farallon Basin where the $C h l_{\max }$ layer was significantly broader with a two-fold higher $C h l_{\max }$ and the solar elevation was significantly lower (see Figure 2). As a result of these differences in the environmental conditions, which could also include differences in the IOPs, some features of AOPs measured in the Farallon Basin were different compared to those in the Guaymas Basin. We note, however, that the data from the Farallon Basin do not extend throughout the entire Chl max layer but end at $40 \mathrm{~m}$ which is about $10 \mathrm{~m}$ below $z_{\text {Chlmax }}$. The values of the average cosines in the blue-green spectral region in the Farallon Basin were much lower (Figure 7a-c) than those in the Guaymas Basin (Figure $5 \mathrm{f}-\mathrm{h}$ ). The lower values of $\bar{\mu}_{d}$ and $\bar{\mu}$ in the blue and green can be explained by the higher solar zenith angle and slightly higher IOPs as indicated by the $c_{p}(z, 660)$ profiles (Figure $2 \mathrm{~b}$ ). This result is consistent with previous experimental and modeling results $[29,60,92-94]$. The observation of very low values $(0.25-0.35)$ of $\bar{\mu}_{u}$ in the blue and green (Figure 7b) will be discussed is some detail in Section 3.2.1, but it is interesting to note that the values less than 0.35 were previously reported on the basis of RT simulations of highly scattering environment within near-surface bubble clouds [91]. In the red where the effects of inelastic processes are strong, the vertical profiles of average cosines exhibited similar features to those described earlier for the station in the Guaymas Basin. Overall, our data of the average cosines support the notion that sun position in a clear sky sets the values of $\bar{\mu}_{d}$ and $\bar{\mu}$ near the ocean surface, which then change with depth in a manner dependent on the interplay of the vertical structure of IOPs and inelastic processes, and $\bar{\mu}_{u}$ may vary within a broader range than commonly assumed. It is thus important to emphasize that the average cosines are sensitive to surface illumination, especially for the downwelling and total light in the near-surface layer, so these average cosines may potentially serve as AOPs or useful descriptors of near-surface water bodies only under specified surface boundary conditions.

The vertical profiles of $R$ in the Farallon Basin (Figure 7d) showed patterns that were similar to those observed in the Guaymas Basin (Figure $5 \mathrm{e}$ ), but the $R$ values were generally higher because of higher $\mathrm{Chl}$ and water turbidity at the station in the Farallon Basin. The properties of particulate assemblages, including the composition and size distribution, could have also been different at these stations. The $K_{d}$ and $K_{u}$ values within the $C h l_{\max }$ layer in the Farallon Basin (Figure 7e,f) were not as low as in the examined case from the Guaymas Basin (Figure 6e,g). This observation also applies to $K_{o d}$ and $K_{o u}$ (not shown in Figure 7). In particular, unlike in the Guaymas Basin case, the chlorophyll-a fluorescence within the much stronger $C h l_{\text {max }}$ layer in the Farallon Basin did not produce a minimum of $K_{u}$ with negative values around the depth of $z_{\text {Chlmax }}$ (Figure $7 \mathrm{f}$ ). This lack of distinct negative minimum of $K_{u}$ can be attributed to the weakening of the effects of inelastic processes when the water column becomes more turbid, as previously demonstrated by RT simulations [60]. In addition, it is also likely that the influence of $C h l_{\max }$ is less profound when the FWHM of the Chl max layer is large, which is the case for the station in the Farallon Basin.

\subsection{Overall Variability and Relationships Involving the Apparent Optical Properties}

In this section we examine the overall variability of AOPs and the relationships involving AOPs and some environmental factors (depth, solar zenith angle, $\mathrm{Chl}$ ) using the entire dataset collected in the Gulf of California. 


\subsubsection{Average Cosines}

As indicated earlier the average cosines serve as simple proxies of the angular structure of the light field and they have or have not been treated as AOPs by different investigators in the past $[9,10,46,48]$. Based on our measurements of irradiance quartet the average cosine of underwater light field, $\bar{\mu}$, ranged from about 0.38 to 0.88 in the blue and green spectral regions. In the red, the range was much larger, from 0.07 to 0.94 , owing to strong effects of inelastic processes. The average cosine for downwelling light field, $\bar{\mu}_{d}$, varied from 0.41 to 0.91 in the blue and green and 0.37 to 0.98 in the red. The approximate range for the average cosine for the upwelling light field, $\bar{\mu}_{u}$, was $0.2-0.5$ in the blue and green and $0.27-0.75$ in the red. Our data are consistent but generally exhibit a broader range of values compared with relatively few experimental data of average cosines reported in literature. Højerslev [18] reported on measurements of $E_{0}, E_{d}$, and $E_{u}$ in the Mediterranean Sea and Norwegian fjord. Using his data, we calculated that $\bar{\mu}$ was in the range of $0.47-0.95$ in the blue-green spectral region $(427,477$, and $532 \mathrm{~nm}$ ) between the sea surface and $70 \mathrm{~m}$ depth, and $0.7-0.97$ in the red $(633 \mathrm{~nm})$ within top $20 \mathrm{~m}$ layer. Spitzer and Wernand [52] reported on measurements of $\bar{\mu}$ in the range $0.7-0.9$ at wavelengths shorter than $600 \mathrm{~nm}$ and depths between 24 and $55 \mathrm{~m}$. Lewis et al. [29] measured the full angular distribution of radiance at a single wavelength of $555 \mathrm{~nm}$ in surface waters of the Pacific Ocean off Hawaii Islands, Santa Barbara Channel, and in Bedford Basin, and used these measurements to determine the ranges for $\bar{\mu}, \bar{\mu}_{d}$, and $\bar{\mu}_{u}$, which were approximately $0.41-0.82,0.5-0.94$, and $0.2-0.48$, respectively. Our determinations in the blue and green are generally consistent with the data from literature. The comparison for the red spectral region is, however, more limited because only few fragmentary data in the red have been previously reported. Our measurements of the average cosines in the red exhibited a very wide range of variability within the water column, providing a more comprehensive characterization of the average cosines that are strongly affected by inelastic processes in this spectral region.

It has long been recognized that at near-surface depths in relatively clear ocean waters, the downwelling radiance distribution, and hence $\bar{\mu}_{d}$, are strongly dependent on the sun position in clear sky or more generally on sky conditions, for example clear skies vs. overcast skies [11]. Such sensitivity of the downwelling average cosine to surface illumination conditions cautions against its indiscriminate use as a general descriptor (in the sense of AOPs) of water bodies, especially in the surface layers, and emphasizes a need for specifying surface boundary conditions. Our data collected within the top $10 \mathrm{~m}$ layer in the Gulf of California support the general trend of a decrease in near-surface $\bar{\mu}_{d}$ with increasing solar zenith angle regardless of light wavelength (Figure 8a). For comparison, the best fit lines to experimental data of Aas and Højerslev [94] obtained at a $5 \mathrm{~m}$ depth (Mediterranean Sea) in the blue (465 and $474 \mathrm{~nm}$ ) and experimental data of Lewis et al. [29] at a $5 \mathrm{~m}$ depth (open ocean waters in the Pacific) in the green (555 nm) are also shown in Figure 8a. In contrast, our data of $\bar{\mu}_{u}$ at near-surface depths did not exhibit a clear dependence on the solar zenith angle (Figure 8b). We note, however, that Aas and Højerslev [94] and Lewis et al. [29] suggested a very weak dependence based on their data, as indicted in Figure 8b.

The increased role of inelastic processes, especially Raman scattering, with increasing depth is illustrated for the average cosines in the red part of the spectrum in Figure 9. This effect was particularly well-pronounced for the downwelling light field in terms of a well-behaved trend of a decrease in $\bar{\mu}_{d}$ with increasing depth towards $\bar{\mu}_{d}=0.5$, which is clearly seen in our data at the two examined wavelengths in the red, $650 \mathrm{~nm}$ and $683 \mathrm{~nm}$ (Figure 9a). The best-fit exponential functions to the data are:

$$
\begin{aligned}
& \bar{\mu}_{d}(650)=0.5058 \exp (-0.0460 z)+0.5140\left(r^{2}=0.828, R M S E=0.061, N=65\right) ; \\
& \bar{\mu}_{d}(683)=0.6512 \exp (-0.0715 z)+0.4659\left(r^{2}=0.855, R M S E=0.067, N=65\right),
\end{aligned}
$$

where $r^{2}$ is the determination coefficient and $N$ the number of observations. A distinct group of outlying data marked in Figure $9 \mathrm{a}$ was collected at significantly larger solar zenith angle $\left(\theta_{s}=57.1^{\circ}\right)$ 
than the remaining data. These outliers were not included in the regression analysis. Whereas at $650 \mathrm{~nm}$ Raman scattering is expected to have a dominant effect, at $683 \mathrm{~nm}$ chlorophyll- $a$ fluorescence can have an additional significant or even dominant effect at certain depths, depending on chlorophyll- $a$ concentration and its variation within the water column. The combined effects of Raman scattering and chlorophyll- $a$ fluorescence at $683 \mathrm{~nm}$ result in faster decrease of $\bar{\mu}_{d}(683)$ with depth from the near surface through the lower portion of the $C h l_{\max }$ layer compared with $\bar{\mu}_{d}(650)$. In addition, in our dataset the interplay of vertically variable chlorophyll- $a$ fluorescence and Raman scattering throughout the water column does not seem to have a noticeable deteriorating effect on the strength of the relationship $\bar{\mu}_{d}(683)$ vs. $z$ as compared with $\bar{\mu}_{d}(650)$ vs. $z$.
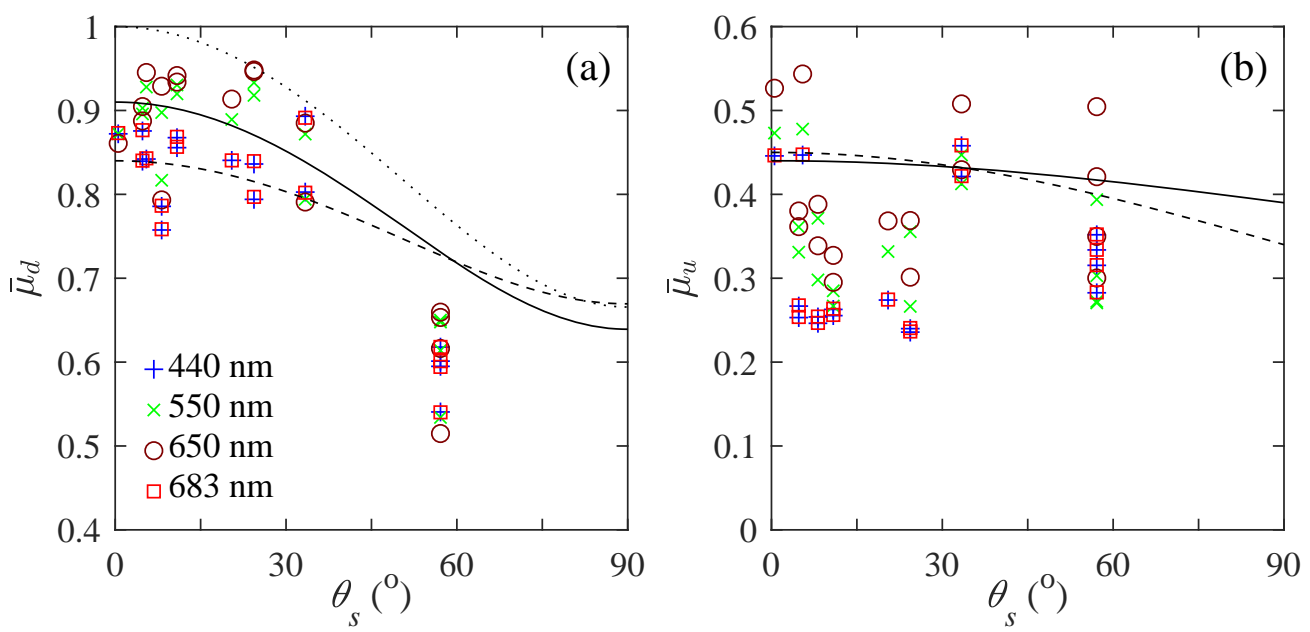

Figure 8. (a) Relationship between $\bar{\mu}_{d}$ at selected light wavelengths as indicated and solar zenith angle $\theta_{s}$. (b) Same as (a) but for $\bar{\mu}_{u}$. The presented data were collected at all stations within the top $10 \mathrm{~m}$ layer. For comparison, solid lines in $(\mathbf{a}, \mathbf{b})$ represent the relationship reported by Lewis et al. [29] and dashed lines by Aas and Højerslev [94]. Dotted line in (a) represents $\bar{\mu}_{d}=\cos \left(\theta_{s w}\right)$ where $\theta_{s w}$ is the zenith angle of the refracted solar beam just beneath the ocean surface obtained from Snell's law.
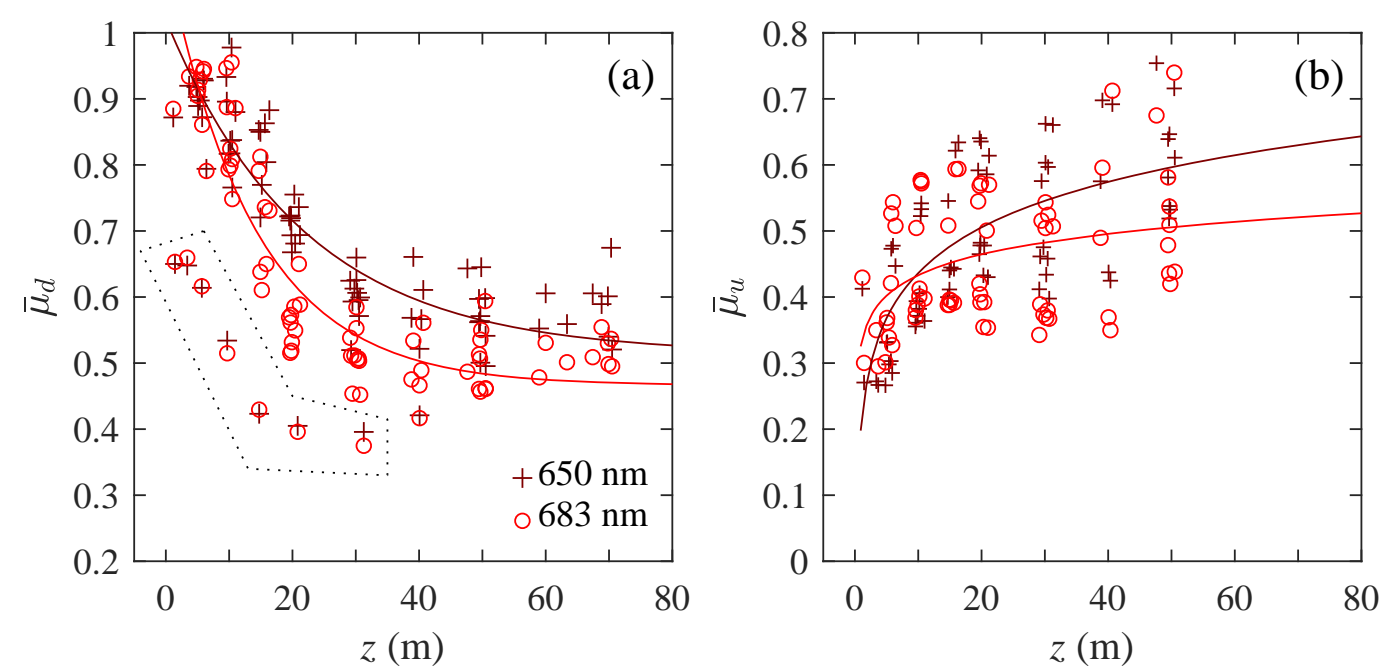

Figure 9. Average cosines in the red spectral bands $(650$ and $683 \mathrm{~nm})$ plotted as a function of depth $z$ using data from all stations and depths. $(\mathbf{a}) \bar{\mu}_{d}(z, 650)$ (crosses) and $\bar{\mu}_{d}(z, 683)$ (open circles) vs. $z$. (b) Same as (a) but for $\bar{\mu}_{u}$. Data points surrounded by dotted lines in (a) are for the station in the Farallon Basin with the solar zenith angle significantly larger $\left(\sim 57^{\circ}\right)$ than at other stations. Solid lines show the best-fit regression functions for the average cosines vs. depth. 
In contrast to $\bar{\mu}_{d}, \bar{\mu}_{u}$ in the red did not exhibit such strong dependence on depth although it is clear that $\bar{\mu}_{u}$ assumed generally lower values near the surface (Figure $9 \mathrm{~b}$ ). The $r^{2}$ values for the $\bar{\mu}_{u}$ vs. $z$ data dropped to 0.488 at $650 \mathrm{~nm}$ and 0.147 at $683 \mathrm{~nm}$. The differences in the patterns of depth dependencies for $\bar{\mu}_{d}$ and $\bar{\mu}_{u}$ can be attributed to relatively smaller role played by inelastic processes at near-surface depths for the downwelling light field compared with the upwelling light field in the red spectral region. It is also important to point out that in comparison with our dataset the dependence of $\bar{\mu}_{d}$ on depth is expected to be reduced for datasets collected in turbid waters, at large solar zenith angles, and/or heavily overcast skies. Under such conditions the near-surface values of $\bar{\mu}_{d}$ are expected to be lower (i.e., closer to 0.5) compared with most of our near-surface data, and hence the expected changes of $\bar{\mu}_{d}$ with depth would not be as well pronounced. Thus, the strong sensitivity of near surface $\bar{\mu}_{d}$ to illumination conditions at the sea surface suggests that no single relationship can describe a change of $\bar{\mu}_{d}$ with depth. This is illustrated in Figure 9a which includes an outlying case of data points collected at significantly larger $\theta_{\mathrm{s}}$ than the remaining data, emphasizing a need to pay particular attention to the possible effect of solar zenith angle. In addition, it is important to emphasize that in the blue-green spectral region where the effects of inelastic processes are weaker, the average cosines exhibited much less distinct dependency on depth (see Figures $5 \mathrm{e}-\mathrm{g}$ and $7 \mathrm{a}-\mathrm{c}$ ).

Our analysis also shows that regardless of light wavelength, none of the average cosines were related significantly to $C h l$ in our dataset. The highest $r^{2}$ of 0.42 was found between $\bar{\mu}_{d}(z, 650)$ and $\operatorname{Chl}(z)$ (not shown). For $\bar{\mu}_{d}$ in the blue-green where inelastic processes are less important than in the red, and for $\bar{\mu}_{u}$ at all examined spectral bands, the relation was much weaker or essentially indiscernible. This lack of relation with $C h l$ is not surprising because the average cosine within the water column, if not dominated by inelastic processes, depends on the interplay of the inherent absorption and scattering properties of seawater in rather complex way [85], and Chl cannot adequately represent such effects.

Similar patterns observed in our data of $\bar{\mu}$ and $\bar{\mu}_{d}$ (e.g., Figure 5) indicate that these two average cosines were well correlated. The relationships between $\bar{\mu}$ and $\bar{\mu}_{d}$ obtained with our data are presented in Figure 10a. Specifically, the linear relationship for the blue-green spectral region as determined from the data collected at various depths and two wavelengths, $440 \mathrm{~nm}$ and $550 \mathrm{~nm}$, is:

$$
\bar{\mu}=0.996 \bar{\mu}_{d}-0.0352 \quad\left(r^{2}=0.978, R M S E=0.042, N=158\right) .
$$

On the basis of data at two wavelengths in the red, 650 and $683 \mathrm{~nm}$, the relationship is:

$$
\bar{\mu}=1.51 \bar{\mu}_{d}-0.472 \quad\left(r^{2}=0.929, R M S E=0.167, N=134\right) .
$$

These relationships indicate that reasonably good estimates of $\bar{\mu}$ can be obtained from downwelling irradiance measurements. As seen, $\bar{\mu}$ and $\bar{\mu}_{d}$ in the blue-green were typically close to one another within the examined euphotic layer. In the red, the correlation is marginally lower and still very strong but $\bar{\mu}$ tends to be somewhat smaller than $\bar{\mu}_{d}$ over a nearly complete data range with the exception of the highest values.

In contrast to $\bar{\mu}$ vs. $\bar{\mu}_{d}$ relationship, $\bar{\mu}_{u}$ and $\bar{\mu}_{d}$ were not correlated or very weakly correlated (Figure 10b). The $r^{2}$ values for the blue-green and red spectral regions are 0.026 and 0.109 , respectively. Therefore, $\bar{\mu}_{u}$ cannot be estimated from $\bar{\mu}_{d}$ or vice versa, which means that a complete irradiance quartet or radiance angular distribution is required for investigating both $\bar{\mu}_{u}$ and $\bar{\mu}_{d}$. Figure $10 \mathrm{~b}$ also reveals that the $\bar{\mu}_{u}$ data in the blue-green appeared to be grouped in at least two distinct clusters, one with $\bar{\mu}_{u}>\sim 0.3$ and the other with $\bar{\mu}_{u}<\sim 0.3$. A large number of $\bar{\mu}_{u}$ measurements fells in the range from 0.2 to $\sim 0.3$, suggesting that much of the upwelling light in these cases propagated relatively close (within $\sim 10^{\circ}-20^{\circ}$ ) to the horizontal direction. This is not consistent with a common assumption that the angular distribution of upwelling light field is more isotropic. Nonetheless, such low values of $\bar{\mu}_{u}$ were also observed by Lewis et al. [29] and reported on the basis of RT simulations within highly-scattering bubble clouds at near-surface depths [91] and for certain combinations of absorption 
coefficient, scattering coefficient, and scattering phase function in the water column (C. Mobley, personal communication). A closer inspection of our data indicates that the group with $\bar{\mu}_{u}<\sim 0.3$ was generally characterized by relatively larger values of $c_{p}(z, 660)$, especially within the top $30-40 \mathrm{~m}$, compared to the group with $\bar{\mu}_{u}>\sim 0.3$. This is seen in the example data shown in Figures $3,5 \mathrm{~b}, \mathrm{f}$ and $7 \mathrm{~b}$, supporting the notion that certain suites of IOPs can play an important role for producing low values of $\bar{\mu}_{u}$.

Although the behavior of average cosines in natural waters can be complex, these quantities are usually assumed to be constant or vertically uniform when used in the context of ocean color remote sensing applications, bio-optical modeling, and/or estimation of water constituents, e.g., [39,95-99]. The assumption that $\bar{\mu}$ obtained from simulations for a homogeneous water column is representative of a stratified water column was also used $[100,101]$. The present study demonstrates that these simplifying assumptions are not valid. Further studies to determine how such assumptions lead to errors in data products of interest are needed. For example, Sathyendranath and Platt [102] reported that oceanic primary productivity could be systematically underestimated by 5 to $13 \%$ when ignoring the angular distribution of the underwater light field, for which the average cosines serve as simple yet useful proxies.
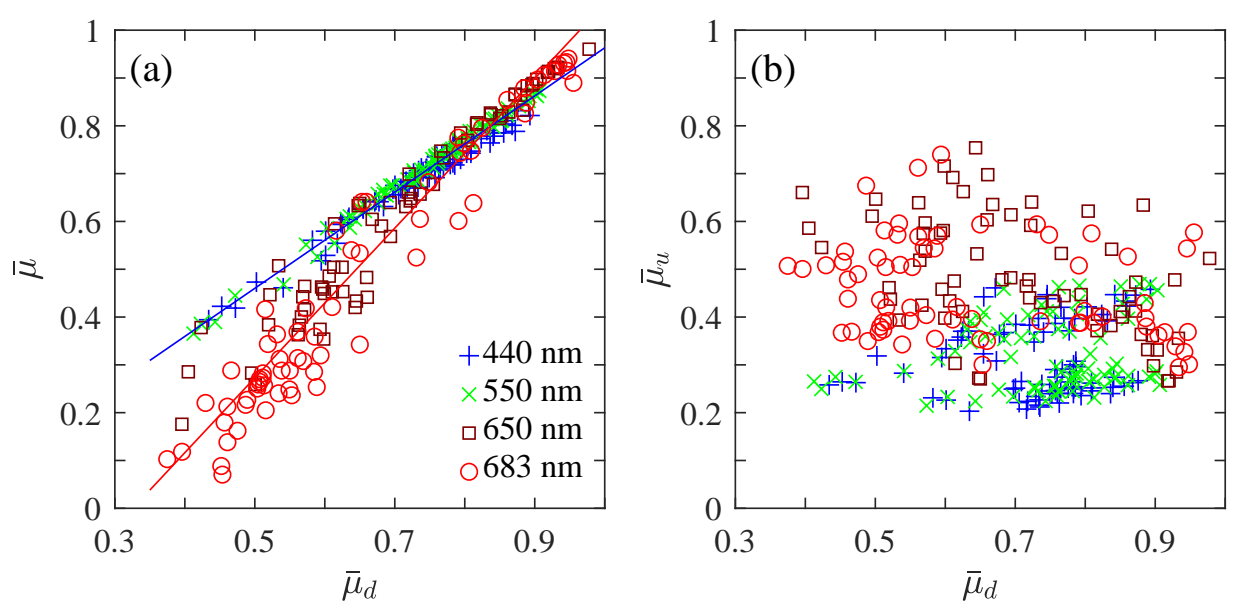

Figure 10. Relationships between average cosines based on measurements from all stations and depths. Data for (a) $\bar{\mu}$ vs. $\bar{\mu}_{d}$ and (b) $\bar{\mu}_{u}$ vs. $\bar{\mu}_{d}$ are shown for selected light wavelengths as indicated in panel (a). In (a) data points for the blue and green (440 nm and $550 \mathrm{~nm}$ ) were combined to determine the best-fit regression function (blue line) and data points for the red (650 nm and $683 \mathrm{~nm}$ ) were combined to determine the best-fit regression function (red line).

\subsubsection{Irradiance Reflectance}

Similar to the average cosines, the variations in the irradiance reflectance, $R$, throughout the euphotic layer are characterized by a much broader range in the red spectral region where the effects of inelastic processes are very strong compared with the blue-green part of the spectrum where these effects are much weaker. Our data of $R$ in the blue-green ranged from 0.006 to 0.056 , whereas in the red from 0.0015 near the surface to 0.75 around $z_{\text {chlmax }}$. The observed range in the blue-green is similar to that of $0.006-0.063$ based on $E_{d}$ and $E_{u}$ measurements reported by Højerslev [18] for 427, 477, 532, and $572 \mathrm{~nm}$ between the surface and $\sim 70 \mathrm{~m}$. The $R$ values at $633 \mathrm{~nm}$ in Højerslev's dataset range from 0.001 to 0.004 , but these values were determined only at shallow depths, typically less than $5 \mathrm{~m}$. Our data in the red extend to much higher values within the euphotic layer owing to strong inelastic effects in this spectral region, which is consistent with a few measurements from undisclosed locations reported by Dirks and Spitzer [37].

As emphasized before, the increasing role of inelastic processes with increasing depth is most significant in the long-wavelength part of the spectrum. This effect is clearly seen in our data of $R$ 
plotted as a function of depth for wavelengths of 650 and $683 \mathrm{~nm}$ (Figure 11). Both $R(650)$ and $R(683)$ showed gradual increase from the values of the order of $10^{-3}$ near the surface to more than 0.1 within the mid- to deep portions of the examined water column. These data suggest that depth can serve as a useful proxy for the vertical changes in $R$ in the red part of the spectrum. The best-fit exponential functions to the data are:

$$
\begin{aligned}
& R(650)=10^{0.7633 \ln (z)-3.6633} \quad\left(r^{2}=0.820, R M S E=0.331, N=74\right) \\
& R(683)=10^{0.7690 \ln (z)-3.2582} \quad\left(r^{2}=0.794, R M S E=0.362, N=74\right) .
\end{aligned}
$$

Whereas these vertical trends in $R$ reflect primarily the increasing effect of Raman scattering with depth, the effects of chlorophyll- $a$ fluorescence were also evident within the $683 \mathrm{~nm}$ band. The values of $R(683)$ were comparable to $R(650)$ near the surface but increased faster with depth owing to increasing $\mathrm{Chl}$ and associated fluorescence until the $C h l_{\max }$ was reached. Consequently, $R(683)$ tended to have the highest values at depths close to $z_{\text {Chlmax }}$, which was about $30 \mathrm{~m}$ for most investigated stations in this study.

The dominant role of Raman scattering and additional complexities caused by chlorophyll- $a$ fluorescence emission in the red spectral region indicate that this part of the spectrum is not well suited for establishing a relationship between $R$ and $C h l$ within the euphotic layer. The analysis of our entire dataset including all measurement depths confirmed the lack of relationship between $R$ in the red and $C h l$ (not shown). For example, a very low determination coefficient $\left(r^{2}\right.$ in the range of $\left.\sim 0.091-0.155\right)$ was found between the log-transformed data of red $(650 \mathrm{or} 683 \mathrm{~nm})$-to-green $(550 \mathrm{~nm})$ reflectance ratios and Chl. In contrast, our data of the blue-to-green reflectance ratio, $R(440) / R(550)$, and Chl collected at all measurement depths exhibited a relationship with significantly higher determination coefficient of 0.608 (not shown). Although this may not seem surprising given the common use of the blue-to-green ratio of ocean surface reflectance (typically the remote-sensing reflectance rather than irradiance reflectance) for estimating surface $\mathrm{Chl}$ in the context of remote sensing applications, e.g., $[103,104]$, it is important to emphasize a distinct difference which is that our data represent irradiance reflectance and $C h l$ measured at different discrete depths within the entire euphotic layer down to depths as high as $\sim 80 \mathrm{~m}$.

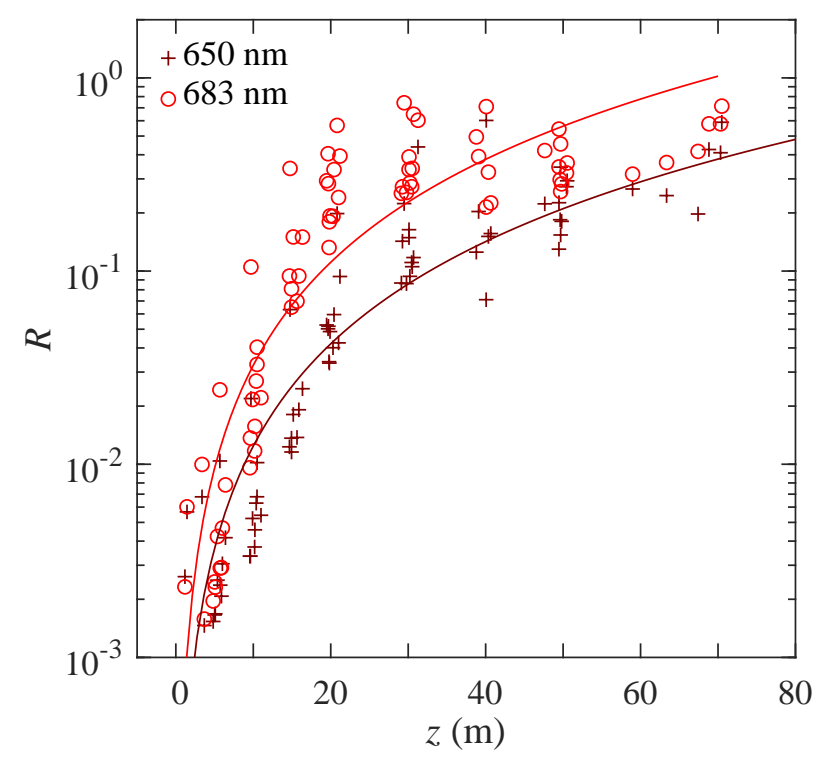

Figure 11. Irradiance reflectance $R$ in the red spectral bands (650 and $683 \mathrm{~nm}$ as indicated) plotted as a function of depth $z$ using data from all stations and depths. Solid lines represent the best-fit regression functions. 


\subsubsection{Diffuse Attenuation Coefficients}

The diffuse attenuation coefficients $K$ in our dataset span a relatively wide range of values. For example, the ranges for $K_{d}$ at $440,550,650$, and $683 \mathrm{~nm}$ are $0.031-0.246,0.054-0.168,0.072-0.514$, and $0.044-0.635 \mathrm{~m}^{-1}$, respectively. The ranges for $K_{u}$ at the same wavelengths are $0.041-0.253$, $0.021-0.192,0.018-0.421$, and $-0.095-0.374 \mathrm{~m}^{-1}$, respectively. The lowest values of $K_{u}$ at longer wavelengths (green and red) were significantly smaller than those for $K_{d}$ and can even include the negative values because the inelastic processes exerted a stronger reducing effect on $K_{u}$ than $K_{d}$. The possibility of negative values of the $K$-coefficients at $685 \mathrm{~nm}$ within the $C h l_{\text {max }}$ layer were also demonstrated through earlier observations and modeling [37].

Because $E_{d}$ has been by far the most commonly measured radiometric quantity in the ocean, $K_{d}$ in the surface layer is relatively well documented in the literature. An overview of early data of $K_{d}$, including the classification of optical water types based on the spectral $K_{d}$ within the top $10 \mathrm{~m}$ layer of the ocean, is given in Jerlov [11]. The range of $K_{d}$ values observed in our study in the blue spectral region indicates that the investigated waters in the Gulf of California fall between the oceanic water Types IB or II and the coastal water Type 1 according to Jerlov's classification. Following an increased interest in ocean color remote sensing in early 1970s and the introduction of the concept of bio-optical state of ocean waters representing a measure of the effect of biological processes on ocean optical properties [105], several studies examined experimental data of $K_{d}$ in the context of the relationship with chlorophyll- $a$ concentration over a broad range of these variables measured in various oceanic waters $[35,38,39,106]$. In those studies, $K_{d}$ was typically estimated to represent the top layer from the ocean surface to one attenuation depth $\left(1 / K_{d}\right)$ or euphotic depth $(1 \%$ of surface PAR). The lowest limiting values of spectral $K_{d}$ for the clearest natural waters were also estimated, for example $0.017 \mathrm{~m}^{-1}$ or $0.00885 \mathrm{~m}^{-1}$ at $440 \mathrm{~nm}, 0.0648 \mathrm{~m}^{-1}$ or $0.05746 \mathrm{~m}^{-1}$ at $550 \mathrm{~nm}$, and $0.35 \mathrm{~m}^{-1}$ or $0.34052 \mathrm{~m}^{-1}$ at $650 \mathrm{~nm}$ by Morel and Maritorena [39] and Smith and Baker [107], respectively. These estimates were generally consistent with the lowest measured values in the datasets presented in $[11,38,39]$ although, to our knowledge, the lowest reported measurements of $K_{d}$ in the blue are $0.012 \mathrm{~m}^{-1}$ at $420 \mathrm{~nm}$ [26]. The lowest $K_{d}$ values in the blue in our dataset are thus 1.8 to 3.5 higher than these previous estimates for the clearest waters. In the red, our data of $K_{d}$ collected within the top $10 \mathrm{~m}$ layer (Figures 6e and $7 \mathrm{e}$ ) are similar or somewhat higher than the previous determinations for the clearest waters. At larger depths, $K_{d}$ in the red was reduced owing to the increasing effect of inelastic processes with depth. This effect on the vertical changes in both $K_{d}$ and $K_{u}$ in the red spectral region is illustrated for our dataset in Figure 12. Both $K$ coefficients decrease considerably with depth. This reduction is more pronounced at $683 \mathrm{~nm}$ than $650 \mathrm{~nm} . K_{u}$ decreased more rapidly than $K_{d}$ and approached a relatively stable level of values at shallower depths (i.e., about 15-20 m) than $K_{d}$. The best-fit exponential functions to the data in Figure 12 are:

$$
\begin{array}{ll}
K_{d}(650)=0.4792 \exp (-0.0451 z)+0.0387 & \left(r^{2}=0.925, R M S E=0.033 \mathrm{~m}^{-1}, N=66\right) \\
K_{d}(683)=0.7229 \exp (-0.0947 z)+0.0846 & \left(r^{2}=0.898, R M S E=0.050 \mathrm{~m}^{-1}, N=66\right) \\
K_{u}(650)=0.5614 \exp (-0.2258 z)+0.0730 & \left(r^{2}=0.806, R M S E=0.032 \mathrm{~m}^{-1}, N=64\right) \\
K_{u}(683)=1.0000 \exp (-0.4711 z)+0.0641 & \left(r^{2}=0.391, R M S E=0.062 \mathrm{~m}^{-1}, N=64\right) .
\end{array}
$$

The relationship for $K_{u}(683)$ is greatly inferior because at this wavelength the effect of Raman scattering is reinforced by chlorophyll- $a$ fluorescence emission, which resulted in a very steep decrease of $K_{u}(683)$ in the top $20 \mathrm{~m}$ (Figure 12b).

In contrast to $K_{d}$, other $K$ coefficients are poorly documented in the literature. It is therefore useful to examine the relationships between $K_{d}$ and other $K$ coefficients using our dataset containing depth-resolved measurements within the euphotic layer. The results from this analysis are shown in Figure 13. Not shown in the figure are results that indicated a very good linear relationship with close agreement between the $K_{d}$ and $K_{o d}$ values $\left(r^{2}=0.985\right)$ and between $K_{u}$ and $K_{o u}\left(r^{2}=0.953\right)$. 
This agreement was generally observed regardless of light wavelength and depth of measurement within our dataset.

The relationship between $K_{u}$ and $K_{d}$ is reasonably good in the blue and green spectral regions (Figure 13a). For example, at 440, 490, and $550 \mathrm{~nm}$ the best-fit linear relationships are:

$$
\begin{aligned}
K_{u}(z, 440)=1.0115 K_{d}(z, 440)+9.47 \times 10^{-3} & \left(r^{2}=0.828, R M S E=0.023 \mathrm{~m}^{-1}, N=66\right) \\
K_{u}(z, 490)=1.0220 K_{d}(z, 490)+1.71 \times 10^{-3} & \left(r^{2}=0.691, R M S E=0.021 \mathrm{~m}^{-1}, N=66\right) \\
K_{u}(z, 550)=1.4699 K_{d}(z, 550)-4.83 \times 10^{-2} & \left(r^{2}=0.672, R M S E=0.023 \mathrm{~m}^{-1}, N=66\right) .
\end{aligned}
$$

As the wavelength increases into the red spectral region the relationship weakens considerably or nearly vanishes as suggested by the large scatter of data points for $650 \mathrm{~nm}$ and $683 \mathrm{~nm}$ in Figure 13a. For these wavelengths, the $r^{2}$ values drop to 0.444 and 0.079 , respectively. This result can be attributed to increased effects of inelastic processes with increasing wavelength, which act differentially on the downwelling and upwelling light attenuation. It is noteworthy that one possible application of the relationships between $K_{u}$ and $K_{d}$ in the blue and green is to use the $K_{d}$ measurements for extrapolating $E_{u}$ measurements to deeper depths where upwelling light is no longer detectable with the $E_{u}$ sensor but is still detectable with the $E_{d}$ sensor. However, a special caution must be exercised for situations with large solar zenith angles, as evidenced by one outlying data point in our dataset which was obtained for relatively large $\theta_{s}$ of $57.1^{\circ}$ compared with the remaining data. While it is known that at large $\theta_{s} K_{d}$ tends to increase significantly in the surface layer [11,17], the effect of solar angle is expected to be less pronounced for $K_{u}$. Such result is seen in our dataset in Figure 6e,f for the near-surface measurements taken at the example station in the Farallon Basin.

Our analysis shows that the linear relationship can be also used for estimating the diffuse attenuation coefficient of net irradiance, $K_{E}$, from $K_{d}$ using the depth-resolved data in the euphotic layer (Figure 13b). For the blue-green spectral region the best-fit relationship is nearly a perfect 1:1 line with the correlation coefficient $r^{2}>0.998$. Specifically, the slope and offset parameters of the linear fit are: 1.0001 and $-1.67 \times 10^{-4} \mathrm{~m}^{-1}$ for $440 \mathrm{~nm}, 0.9999$ and $1.66 \times 10^{-5} \mathrm{~m}^{-1}$ for $490 \mathrm{~nm}$, and 1.0015 and $1.78 \times 10^{-5} \mathrm{~m}^{-1}$ for $550 \mathrm{~nm}$ ( $N=66$ for each wavelength). For the red spectral region, the best fit parameters are still very close to the $1: 1$ line, specifically 0.9746 and $1.26 \times 10^{-2} \mathrm{~m}^{-1}$ for $650 \mathrm{~nm}$ and 0.9857 and $1.92 \times 10^{-2} \mathrm{~m}^{-1}$ for $683 \mathrm{~nm}\left(\mathrm{~N}=62\right.$ for each wavelength). The $r^{2}$ values at these wavelengths are only slightly lower than in the blue-green region and remained above 0.965 . These results indicate that the magnitudes and behavior of $K_{E}$ throughout the water column were consistent with those of $K_{d}$ regardless of the spectral region including the long-wavelength portion of the spectrum where the effects of inelastic processes are strongest. Therefore, the use of a single relationship between $K_{E}$ and $K_{d}$ may be satisfactory regardless of wavelength. Such relationship determined from the combined data collected at wavelengths of 440,550 , and $650 \mathrm{~nm}$ is:

$$
K_{E}(z)=1.0093 K_{d}(z)+7.88 \times 10^{-4} \quad\left(r^{2}=0.996, R M S E=0.006 \mathrm{~m}^{-1}, N=194\right) .
$$

This relationship is plotted in Figure 13b. It can be useful when $K_{E}$ is required, for example for the analysis of Gershun's equation, when $E_{d}$ measurements are available but are not accompanied by $E_{u}$ measurements.

Similar to $K_{E}$ vs. $K_{d}$, the linear relationship between the $K_{o}$ and $K_{d}$ values measured throughout the water column is also quite robust regardless of light wavelength (Figure 13c). The plotted regression line corresponds to the best fit obtained from the combined data collected at 440,550, and $650 \mathrm{~nm}$ :

$$
K_{o}(z)=0.9480 K_{d}(z)-1.24 \times 10^{-3} \quad\left(r^{2}=0.984, R M S E=0.015 \mathrm{~m}^{-1}, N=192\right) .
$$

This type of relationship can be useful in the absence of scalar irradiance measurements throughout the water column which is a common situation, but when the measurement or estimate of spectral $E_{o}$ 
just below the surface is available. In such case, $E_{0}$ can be propagated throughout the water column on the basis of vertical measurements of spectral $E_{d}$ using the relationship between $K_{o}$ and $K_{d}$. The resulting depth profile of spectral $E_{O}$ can, in turn, be subject to conversion to quantum units and spectral integration to obtain the depth-resolved PAR quantum scalar irradiance, $E_{O P A R}$.

Assuming the availability of $E_{O P A R}$ just below the surface, e.g., [108], another relationship between the $K$ coefficients can be useful for estimating $E_{O P A R}$ at different depths from vertical measurements of spectral $E_{d}$. This relationship of $K_{O P A R}$ vs. $K_{d}$ on the basis of data collected throughout the water column is shown in Figure 13d. In this analysis we ignored, however, the data collected at near-surface depths $(<5 \mathrm{~m})$ because $K_{O P A R}$ decreases rapidly with depth within the near-surface layer owing to high absorption by water molecules within the long-wavelength portion of the spectrum [10,109-111]. Figure $13 \mathrm{~d}$ demonstrates that there is a reasonably good linear relationship between $K_{o P A R}$ and $K_{d}$ in the blue and green spectral regions, as illustrated for $440 \mathrm{~nm}, 490 \mathrm{~nm}$, and $550 \mathrm{~nm}$. The best-fit relationships are:

$$
\begin{array}{ll}
K_{o P A R}(z)=0.5643 K_{d}(z, 440)+3.07 \times 10^{-2} & \left(r^{2}=0.911, R M S E=0.029 \mathrm{~m}^{-1}, N=54\right) \\
K_{o P A R}(z)=0.8504 K_{d}(z, 490)+2.41 \times 10^{-2} & \left(r^{2}=0.923, R M S E=0.015 \mathrm{~m}^{-1}, N=54\right) \\
K_{o P A R}(z)=1.2256 K_{d}(z, 550)-2.52 \times 10^{-2} & \left(r^{2}=0.856, R M S E=0.012 \mathrm{~m}^{-1}, N=54\right) .
\end{array}
$$

A closer examination also showed that $K_{P A R}(z) \approx\left[K_{d}(z, 490)+K_{d}(z, 550)\right] / 2$ :

$$
\begin{gathered}
K_{\text {oPAR }}(z)=1.0182\left[K_{d}(z, 490)+K_{d}(z, 550)\right] / 2-2.61 \times 10^{-3} \\
\left(r^{2}=0.908, R M S E=0.010 \mathrm{~m}^{-1}, N=54\right) .
\end{gathered}
$$

Being very close to the 1:1 line, this relationship provides a convenient approximation to $K_{\text {oPAR }}(z)$ based on $K_{d}(z)$ and is plotted in Figure 13d.

Because of unavailability or scarcity of scalar irradiance measurements, the measurements of downward plane irradiance have been typically used in the past for estimating photosynthetically available radiation in terms of PAR quantum downward irradiance, $E_{d P A R}[11,105,109-111]$. Kirk [10] provides a comprehensive overview of $K_{d P A R}$ values for various oceanic, coastal, estuarine, and inland aquatic environments. Our dataset shows a strong linear relationship between $K_{O P A R}$ and $K_{d P A R}$ throughout the examined water column (Figure 13e):

$$
K_{o P A R}(z)=0.9516 K_{d P A R}(z)-3.12 \times 10^{-3} \quad\left(r^{2}=0.937, R M S E=0.012 \mathrm{~m}^{-1}, N=54\right) .
$$

This relationship provides an alternative to Equation (10d) for the use in a situation when $E_{O P A R}$ just below the surface and vertical measurements of spectral $E_{d}$ are available.

It is noteworthy to mention that because of widespread interest in the determinations of remote-sensing reflectance the contemporary underwater radiometric systems are often configured to include only two sensors, one for the spectral measurements of $E_{d}$ and another for the spectral measurements of upwelling zenith radiance, $L_{u}$. Because such systems lack the measurement of $E_{u}$, it is useful to examine the relationship between $K_{u}$ and $K_{L u}$. The analysis of our dataset indicates that a single linear relationship provides reasonably good estimates of $K_{u}$ from $K_{L u}$ regardless of light wavelength and depth (Figure 13f):

$$
K_{u}=0.9838 K_{L u}-0.0010 \quad\left(r^{2}=0.905, R M S E=0.016 \mathrm{~m}^{-1}, N=52\right) .
$$

This relationship was obtained from data collected at three wavelengths, 440, 550, and $650 \mathrm{~nm}$. Note that the slope coefficient of the regression is close to 1 but many data points of $K_{u}$ in the blue and green spectral bands are higher than $K_{L u}$. This tendency is not seen in the red band, however. 

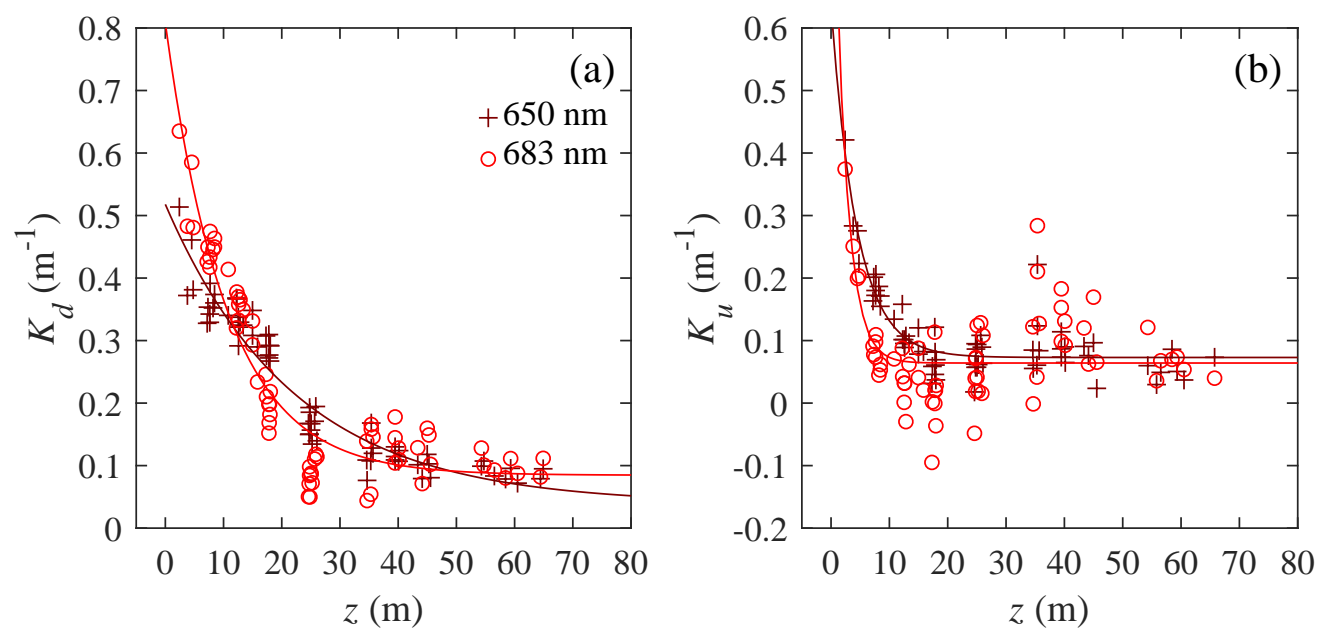

Figure 12. Diffuse attenuation coefficients in the red spectral bands (650 and $683 \mathrm{~nm})$ plotted as a function of depth $z$ using data from all stations and depths. (a) $K_{d}(z, 650)$ (crosses) and $K_{d}(z, 683)$ (open circles) vs. $z$. (b) Same as (a) but for $K_{\mathrm{u}}$. Solid lines represent the best-fit regression functions.
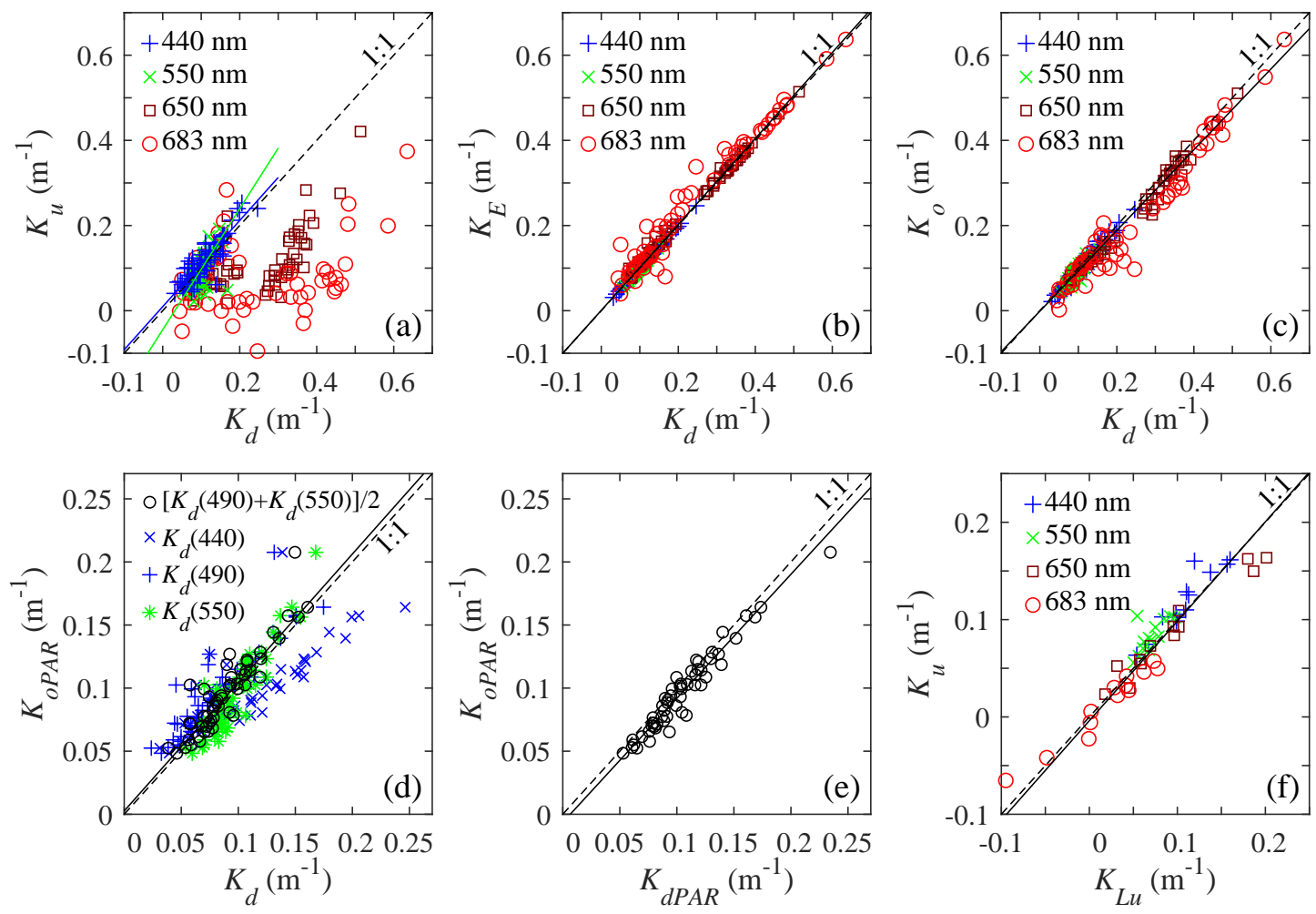

Figure 13. Relationships between diffuse attenuation coefficients based on measurements from all stations and depths. (a) $K_{u}$ vs. $K_{d} ;$ (b) $K_{E}$ vs. $K_{d} ;$ (c) $K_{o}$ vs. $K_{d}$. (d) $K_{d P A R}$ vs. $K_{d} ;\left(\right.$ e) $K_{o P A R}$ vs. $K_{d P A R}$; and (f) $K_{u}$ vs. $K_{L u}$. In (a-c,f), different symbols represent data at different light wavelengths as indicated. In (d) symbols indicate the relationships between $K_{O P A R}(z)$ and different $K$-coefficients as indicated, including the relationship between $K_{O P A R}(z)$ and $\left[K_{d}(z, 490)+K_{d}(z, 550)\right] / 2$. The best fit regression functions (solid lines) are shown for (a) data at $440 \mathrm{~nm}$ and $550 \mathrm{~nm}$ analyzed separately, (b,c) combined data at $440 \mathrm{~nm}, 550 \mathrm{~nm}$, and $650 \mathrm{~nm}$, (d) data of $K_{o P A R}(z)$ vs. $\left[K_{d}(z, 490)+K_{d}(z, 550)\right] / 2$, and (e,f) all data displayed in these panels. Dashed lines represent the 1:1 agreement between the variables. 


\subsection{Application of Gershun's Equation}

The underwater radiometric measurements in conjunction with the use of Gershun's equation provide a method for determining the absorption coefficient of seawater, $a(\lambda, z)$, as a product of $K_{E}(\lambda, z)$ and $\bar{\mu}(\lambda, z)$. The main limitation of this radiometric method is that Gershun's equation was derived from a simplified radiative transfer equation that ignores inelastic processes of Raman scattering and fluorescence and internal sources (i.e., true light emission) such as bioluminescence, e.g., $[9,11,49]$. Therefore, in principle, this method can work satisfactorily only for cases in which the contributions of inelastic processes and internal sources are negligible. Because bioluminescence is typically intermittent and discrete under natural conditions in the ocean, the primary limitation of the applicability of Gershun's equation in the upper ocean or euphotic layer is associated with the presence of inelastic processes. In spite of these limitations, this radiometric method offers a unique benefit resulting from the estimation of the absorption coefficient that is representative of relatively large volume of seawater. This is because the radiometric measurements and AOPs are representative of much larger volumes of water compared with small volumes involved in direct IOP measurements including in situ absorption meters.

We examined the applicability of the radiometric method using our data collected at two stations, one in the Carmen Basin and another in the Farallon Basin (see Figure 1), where concurrent radiometric and ac-9 measurements were made. In this analysis, we compare the values of the absorption coefficient, $a_{a c 9}(z, \lambda)$, measured with the ac- 9 instrument with those derived from Gershun's equation, i.e., $a_{A O P}(z$, $\lambda)=K_{E}(z, \lambda) \cdot \bar{\mu}(z, \lambda)$. In order to enable such comparison, the data of $a_{a c 9}(z, \lambda)$ and $\bar{\mu}(z, \lambda)$ were adjusted to common depths corresponding to the determinations of $K_{E}(z, \lambda)$. Specifically, $\bar{\mu}(z, \lambda)$ was linearly interpolated to obtain the values for depths at which $K_{E}(z, \lambda)$ was determined, i.e., the mid-points between the discrete depths (see Equation (1)) where the radiometric measurements, and hence $\bar{\mu}(z, \lambda)$, were made. The high depth resolution ac-9 data required only minor interpolation to these mid-point depths. In addition, the high spectral resolution data of $K_{E}(z, \lambda)$ and $\bar{\mu}(z, \lambda)$ were linearly interpolated to ac-9 wavelengths. Our comparative analysis of $a_{A O P}(z, \lambda)$ and $a_{a c}(z, \lambda)$ is focused on five ac-9 wavelengths, 440, 488, 555, 650, and $676 \mathrm{~nm}$.

In addition to the effects of inelastic processes and mismatch of spatial scales of AOP and ac-9 measurements, it is noteworthy to mention other sources of uncertainty that can affect the comparisons of $a_{a c 9}(z, \lambda)$ and $a_{A O P}(z, \lambda)$. The accurate direct in situ measurements of $a(z, \lambda)$ with instruments such as ac-9 are difficult, mainly because of scattering error and stringent calibration requirements [112-114]. The determinations of $K_{E}(z, \lambda)$ and $\bar{\mu}(z, \lambda)$ require measurements with four $\left(E_{d}, E_{u}, E_{o d}, E_{o u}\right)$ or at least three $\left(E_{d}, E_{u}, E_{o}\right)$ radiometric sensors, so these determinations are critically dependent on accurate calibrations of multiple sensors. The accuracy of determinations of $K_{E}(z, \lambda)$ for specific depths can be also affected by relatively low depth resolution of radiometric measurements that were taken at several discrete depths in our study.

In spite of multiple sources of uncertainty, we found reasonably good agreement between $a_{A O P}$ and $a_{a c}$ throughout the euphotic layer for the blue and green spectral regions where the effects of inelastic processes were relatively weak (Figure 14a-c). As shown for the example data collected in the Farallon Basin, the applicability of Gershun's equation within the examined water column extends from the short-wavelength portion of the spectrum to about $580 \mathrm{~nm}$, as indicated by the vertical dotted line in Figure 14a. At longer wavelengths this application failed owing to stronger effects of Raman scattering and chlorophyll- $a$ fluorescence, even at the shallowest depth of $7.2 \mathrm{~m}$ examined in this case (Figure 14a,b). As the Raman scattering effects continue to accumulate with increasing depth the short-wavelength boundary of the affected spectral region is expected to shift towards shorter wavelengths $[60,64,73]$. Therefore, one can expect that at depths greater than those examined in our study the application of Gershun's equation may fail for wavelengths shorter than $\sim 580 \mathrm{~nm}$. Figure $14 \mathrm{~b}$ also shows that somewhat larger discrepancy between $a_{A O P}$ and $a_{a c}$ at $440 \mathrm{~nm}$ was observed within the $C h l_{\max }$ layer around the depth of $z_{\text {Chlmax }}$. This may be associated with the limitation that the radiometric measurements were taken at discrete depths with relatively low depth 
resolution (i.e., $10 \mathrm{~m}$ below $z=20 \mathrm{~m}$ ), as opposed to nearly continuous depth profiles which would be required for better determinations of $K_{E}(z, \lambda)$ within the optically heterogeneous layer.
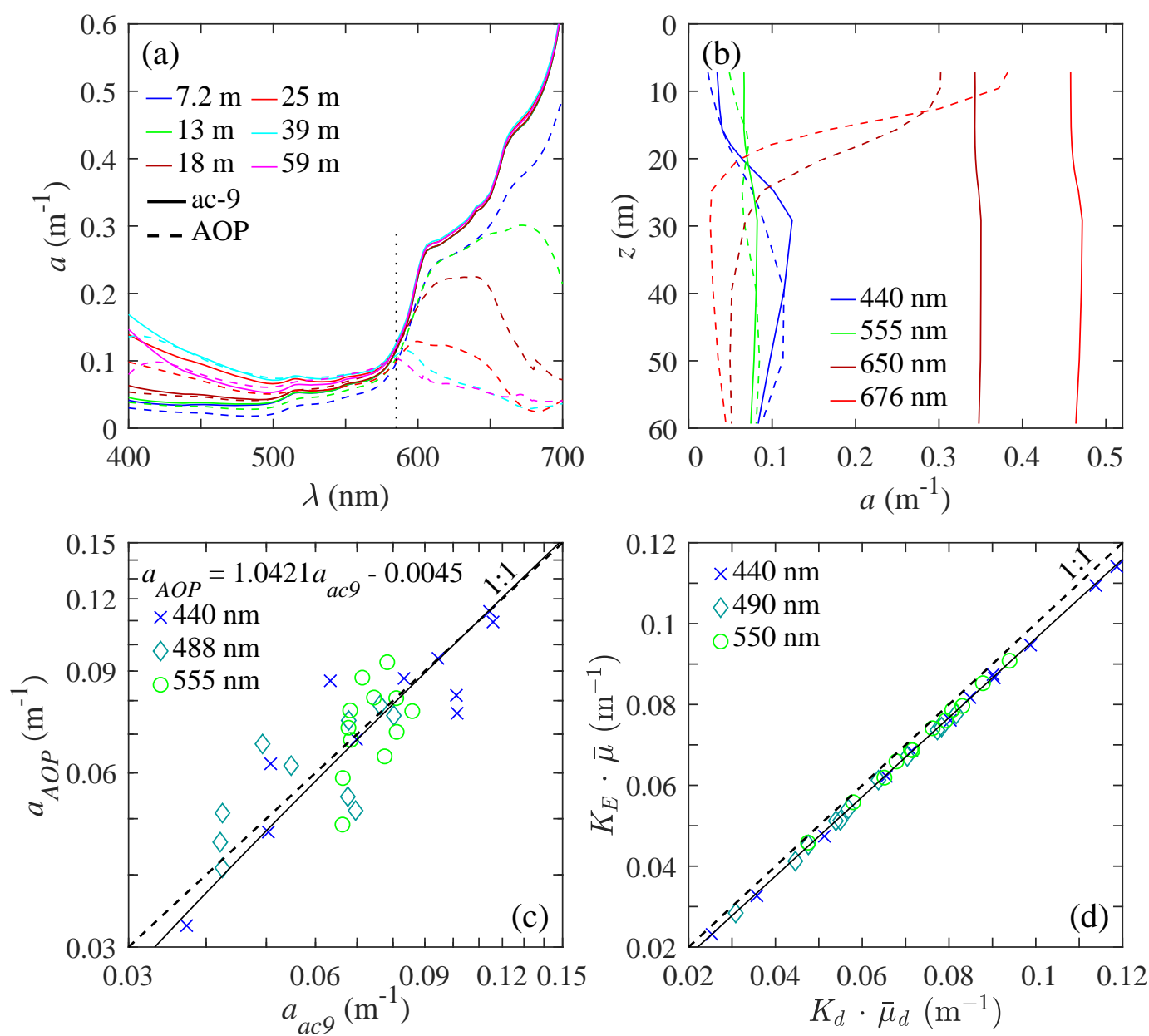

Figure 14. Comparison of the absorption coefficient of seawater measured with an ac-9 instrument $\left(a_{a c}\right)$ and estimated from AOPs using the irradiance quartet measurements and Gershun's equation $\left(a_{A O P}\right)$. (a) Spectra of absorption coefficient at depths for which the determinations of $K_{E}$ were made on the basis of radiometric measurements taken at one station in the Carmen Basin where ac- 9 measurements were made during the 2011 cruise. The vertical dotted line indicates the transition region to long-wavelength portion of the spectrum where the use of Gershun's is inadequate because of the effects of inelastic processes. (b) Vertical profiles of absorption coefficient measured with the ac- 9 instrument (solid lines) and estimated from AOPs (dashed lines) at selected light wavelengths as indicated. Data were collected at the same station as in panel (a). (c) Direct comparison between $a_{A O P}$ and $a_{a c 9}$ at selected blue and green spectral bands as indicated. Data were collected at one station in the Guaymas Basin and one station in the Carmen Basin where ac- 9 measurements were made during the 2011 cruise. (d) Relationship between $K_{E} \cdot \bar{\mu}$ and $K_{d} \cdot \bar{\mu}_{d}$ for the blue-green spectral regions based on data at the three selected light wavelengths as indicated. Solid lines in (c,d) represent the best-fit regression functions and dashed lines the 1:1 agreement between the variables.

Figure 14c shows that $a_{A O P}$ and $a_{a c 9}$ compare favorably for the combined dataset from the two stations, which includes data points for the three wavelengths from the blue-green spectral region $\left(440,488\right.$, and $555 \mathrm{~nm}$ ) and all discrete depths included in this analysis (i.e., where $K_{E}$ was determined). The best linear fit to the data is very close to the 1:1 line and the correlation is strong $\left(r^{2}=0.750\right)$. This was the only case in this study when Model II regression analysis was applied (see Section 2.6). If the ac-9-measured values are tentatively assumed to represent true values, then the 
statistical indicators suggest a very small bias of $a_{A O P}$ estimates as the median value for the ratio of $a_{A O P} / a_{a c 9}$ is very close to $1(0.989)$ and the mean difference between $a_{A O P}$ and $a_{a c 9}$ is very small $\left(-0.0016 \mathrm{~m}^{-1}\right)$. The median absolute percent difference between $a_{A O P}$ and $a_{a c 9}$ is $12.4 \%$ and the root mean square deviation is $0.0116 \mathrm{~m}^{-1}$.

Because of tight relationships $\bar{\mu}$ vs. $\bar{\mu}_{d}$ (Figure 10a) and $K_{E}$ vs. $K_{d}$ (Figure 13b), it is natural to expect a good relationship between the products $K_{E} \cdot \bar{\mu}$ and $K_{d} \cdot \bar{\mu}_{d}$. This is indeed the case as shown for our data combining the three wavelengths from the blue-green spectral region $(440,490$, and $550 \mathrm{~nm})$ and all examined discrete depths at all stations (Figure 14d). The best-fit linear fit to the data is:

$$
K_{E} \cdot \bar{\mu}=0.980 K_{d} \cdot \bar{\mu}_{d}-0.0017\left(r^{2}=0.999, R M S E=0.003 m^{-1}, N=36\right) .
$$

By indicating that $K_{E} \cdot \bar{\mu}$ can be quite accurately estimated from $K_{d} \cdot \bar{\mu}_{d}$, this relationship has important practical ramifications. Specifically, the measurements of three $\left(E_{d}, E_{u}, E_{0}\right)$ or four $\left(E_{d}, E_{u}\right.$, $\left.E_{o d}, E_{o u}\right)$ irradiances required for determining the absorption coefficient from Gershun's equation can be replaced with just two downwelling irradiance measurements $\left(E_{d}\right.$ and $\left.E_{o d}\right)$, thus significantly simplifying the experimental requirements. We note that the use of two AOPs based on the downwelling light field, $K_{d}$ and $\bar{\mu}_{d}$, has been previously introduced in the context of estimation of absorption by phytoplankton and CDOM, as well as chlorophyll- $a$ concentration from measurements of $E_{d}$ alone $[96,115]$. The modeling formalism based on $E_{d}$ alone required assumptions about $\bar{\mu}_{d}$ and the backscattering coefficient of seawater.

\section{Summary}

Although quantitative radiometric measurements in the ocean have a long-recorded history with the beginning in the early 1930s, the measurements of scalar irradiance have been rare and simultaneous measurements of downward and upward plane and scalar irradiances $\left(E_{d}, E_{u}, E_{o d}\right.$, and $\left.E_{o u}\right)$, the so-called irradiance quartet, are virtually lacking. To our knowledge, this is the first-ever study to report data of high spectral resolution measurements of irradiance quartet within the ocean euphotic layer and the apparent optical properties (AOPs) derivable from this quartet, including a complete set of average cosines characterizing the angular structure of underwater light field, i.e., the downwelling $\left(\bar{\mu}_{d}\right)$, upwelling $\left(\bar{\mu}_{u}\right)$, and total $(\bar{\mu})$ light field. Because the experimental irradiance data collected in the past have been fragmentary in terms of incomplete set of irradiances or limited spectral coverage in rare experiments when $E_{d}, E_{u}$, and $E_{o}$ were measured directly or derived from radiance measurements, currently available descriptions and understanding of underwater light field and AOPs associated with a complete irradiance quartet have relied mostly on theoretical simulations of radiative transfer in the ocean. Such simulations unavoidably involve some idealized assumptions about the real environment. Thus, the experimental data presented in this paper provide a unique and revealing resource on the patterns of irradiance quartet and associated suite of AOPs within a real water column that was characterized by the interplay of non-uniform vertical distribution of inherent optical properties (IOPs) of seawater and the effects of inelastic radiative processes such as Raman scattering by water molecules and chlorophyll- $a$ fluorescence.

Our dataset was collected in the Gulf of California within the euphotic layer from the near-surface depths to $\sim 80 \mathrm{~m}$ and covered a broad range of IOPs, sky conditions, and solar zenith angle. Our data show that in the blue and green spectral regions, the vertical patterns of AOPs were driven primarily by IOPs of seawater with weak or no discernible effects of inelastic radiative processes. In contrast, in the red spectral region the radiometric variables characterizing the light field and the AOPs were strongly affected or totally dominated by inelastic processes of Raman scattering, and additionally by chlorophyll- $a$ fluorescence within the fluorescence emission band, the latter being particularly well-pronounced within the chlorophyll- $a$ maximum layer. Some of the most notable features caused by inelastic processes in the red include the values of average cosines which approached those of the uniform light field, exceptionally high values of irradiance reflectance $R$ approaching 
1 , and exceptionally low values (i.e., smaller than the seawater absorption coefficient) of the diffuse attenuation coefficients, $K$, for various irradiances, including the negative values for the attenuation of upwelling irradiances in the chlorophyll- $a$ fluorescence emission band within the chlorophyll- $a$ maximum layer.

Whereas details of the vertical patterns in the light field characteristics and AOPs depended on the interplay of inelastic processes and vertically non-uniform IOPs including the chlorophyll- $a$ concentration, there were general vertical patterns associated with an increase in the contribution of inelastically produced light with increasing depth. We observed, for example, that the vertical patterns of some AOPs in the red, such as $\bar{\mu}_{d}, \bar{\mu}, R, K_{d}$, and $K_{u}$, can be approximated by relatively simple functions of depth. We also established empirical relationships between some AOPs, which can be useful in common experimental situations when only data on downwelling plane irradiance are available. For example, we proposed single relationships for estimating $K_{E}(z)$ and $K_{o}(z)$ from $K_{d}(z)$ at any depth $z$ within the examined depth range regardless of light wavelength. Similarly, we also determined that a single relationship can be used for estimating $K_{u}(z)$ from $K_{d}(z)$ within the blue-green spectral region, in which the effects of inelastic processes are generally weak. Our results also demonstrated that below the near-surface layer (i.e., $z$ approximately greater than $5 \mathrm{~m}$ in our dataset) the values of $K_{O P A R}(z)$ can be estimated from measurements of $K_{d}(z)$ in the blue-green bands using a single relationship. Typically, the empirical relationships are expected to be applicable within a range of environmental conditions consistent with the dataset used in the development of the relationships. This limitation also applies to the relationships established in this study, in which we covered a fairly broad range of conditions (Table 2).

We tested the use of irradiance quartet measurements in conjunction with Gershun's equation for estimating the absorption coefficient of seawater and found that in the blue-green spectral region such estimates agree reasonably well with direct determinations of the absorption coefficient from measurements with the ac- 9 instrument. As the Gershun equation is inadequate in situations when inelastic processes are significant, no agreement was observed at light wavelengths longer than about $580 \mathrm{~nm}$. Specifically, in the long-wavelength portion of the spectrum the absorption coefficients estimated from Gershun's equation were greatly underestimated due to the effects of inelastic processes. The analysis of our data from the entire examined depth range also showed that the product of two AOPs in the blue-green spectral region, $K_{E} \cdot \bar{\mu}$, which is used for estimating the absorption coefficient from Gershun's equation, can be adequately estimated from the product $K_{d} \cdot \bar{\mu}_{d}$. This is potentially useful because the determinations of $K_{E} \cdot \bar{\mu}$ require the measurements of irradiance quartet or at least three irradiances $E_{d}(z), E_{u}(z)$, and $E_{o}(z)$, whereas the determinations of $K_{d} \cdot \bar{\mu}_{d}$ require a simpler experimental design with only two irradiances, $E_{d}$ and $E_{o d}$.

Author Contributions: L.L. and D.S. wrote the paper; M.D. collected the field data; L.L. and M.D. processed the data; L.L. analyzed the data; and all authors made intellectual contributions and reviewed the manuscript.

Acknowledgments: This study was supported by the U.S. Office of Naval Research (grant N00014-09-1-1053) as part of the Department of Defense Multidisciplinary University Research Initiative (MURI) Program. Partial support for Linhai Li was provided by the Scripps Institution of Oceanography. The scientists, crew members, and officers of R/V New Horizon are acknowledged for providing logistical support and help during the field work. In particular, we thank Alison Sweeney for providing data from CTD measurements and Yakir Gagnon for ac-9 data. We also thank Rick A. Reynolds and anonymous reviewers for providing comments on the manuscript.

Conflicts of Interest: The authors declare no conflict of interest.

\section{References}

1. Lewis, M.R.; Carr, M.E.; Feldman, G.C.; Esaias, W.; McClain, C. Influence of penetrating solar-radiation on the heat-budget of the equatorial Pacific Ocean. Nature 1990, 347, 543-545. [CrossRef]

2. Lee, Z.P.; Du, K.P.; Arnone, R.; Liew, S.C.; Penta, B. Penetration of solar radiation in the upper ocean: A numerical model for oceanic and coastal waters. J. Geophys. Res. 2005, 110, C09019. [CrossRef]

3. Field, C.B.; Behrenfeld, M.J.; Randerson, J.T.; Falkowski, P. Primary production of the biosphere: Integrating terrestrial and oceanic components. Science 1998, 281, 237-240. [CrossRef] [PubMed] 
4. Mobley, C.D.; Chai, F.; Xiu, P.; Sundman, L.K. Impact of improved light calculations on predicted phytoplankton growth and heating in an idealized upwelling-downwelling channel geometry. J. Geophys. Res. Oceans 2015, 120, 875-892. [CrossRef]

5. Smith, R.C; Wilson, W.H., Jr. Photon scalar irradiance. Appl. Opt. 1972, 11, 934-938. [CrossRef] [PubMed]

6. Booth, C.R. The design and evaluation of a measurement system for photosynthertically active quantum scalar irradiance. Limnol. Oceanogr. 1975, 21, 326-336. [CrossRef]

7. Højerslev, N.K. Daylight measurements appropriate for photosynthetic studies in natural sea waters. J. Cons. Int. Explor. Mer 1978, 38, 131-146. [CrossRef]

8. Morel, A. Available, usable, and stored radiant energy in relation to marine photosynthesis. Deep-Sea Res. 1978, 25, 673-688. [CrossRef]

9. Mobley, C.D. Light and Water: Radiative Transfer in Natural Waters; Academic Press: San Diego, CA, USA, 1994.

10. Kirk, J.T. Light and Photosynthesis in Aquatic Ecosystems; Cambridge University Press: Cambridge, UK, 1994.

11. Jerlov, N.G. Marine Optics; Elsevier Scientific Publishing Company: Amsterdam, The Netherlands, 1976.

12. Jerlov, N.G. Optical studies of ocean water. Rep. Swed. Deep-Sea Exped. 1951, 3, 1-59.

13. Tyler, J.E.; Smith, R.C. Measurements of Spectral Irradiance Underwater; Gordon \& Breach Publishing Group: Philadelphia, PA, USA, 1970.

14. Jerlov, N.G.; Liljequist, G.H. On the angular distribution of submarine daylight and on the total submarine illumination. Svenska Hydrografisk-Biologiska Kommisionens Skrifter Ny Serie Hydrografi 1938, 14, 1-15.

15. Whitney, L.V. The angular distribution of characteristic diffuse light in natural waters. J. Mar. Res. 1941, 4, 122-131.

16. Smith, R.C. Structure of solar radiation in the upper layers of the sea. In Optical Aspects of Oceanography; Jerlov, N.G., Steemann, E., Eds.; Academic Press: San Diego, CA, USA, 1974; pp. 95-117.

17. Lundgren, B.; Højerslev, N.K. Daylight Measurements in the Sargasso Sea: Results from the "Dana" Expedition January-April 1966. Report 14; University of Copenhagen, Institution of Physical Oceanography: Copenhagen, Denmark, 1971.

18. Højerslev, N.K. Inherent and Apparent Optical Properties of the Western Mediterranean and the Hardangerfjord. Report 21; University of Copenhagen, Institution of Physical Oceanography: Copenhagen, Denmark, 1973.

19. Ochakovskiy, Y.Y.; Kopelevich, O.V.; Voytov, V.I. Light in the Sea; (Edited translation from Russian) FTD-HT-24-105-72; Foreign Technology Division, Air Force System Command, US Air Force; National Technical Information Service, U.S. Department of Commerce: Springfieldm, VA, USA, 1972.

20. Voss, K.J. Electro-optic camera system for measurement of the underwater radiance distribution. Opt. Eng. 1989, 28, 384-387. [CrossRef]

21. Dickey, T.; Frye, D.; Jannasch, H.; Boyle, E.; Manov, D.; Sigurdson, D.; McNeil, J.; Stramska, M.; Michaels, A.; Nelson, N.; et al. Initial results from the Bermuda testbed mooring program. Deep Sea Res. Part I 1998, 45, 771-794. [CrossRef]

22. Hooker, S.B.; Maritorena, S. An evaluation of oceanographic radiometers and deployment methodologies. J. Atmos. Ocean. Technol. 2000, 17, 811-830. [CrossRef]

23. Clark, D.K.; Feinholz, M.; Yarbrough, M.; Johnson, B.C.; Brown, S.W.; Kim, Y.S.; Barnes, R.A. Overview of the radiometric calibration of MOBY. In Earth Observing Systems VI; Barres, W.L., Ed.; SPIE Proceedings; SPIE: Bellingham, WA, USA, 2002; Volume 4483, pp. 64-76. [CrossRef]

24. Bulgarelli, B.; Zibordi, G.; Berthon, J.F. Measured and modeled radiometric quantities in coastal waters: Toward a closure. Appl. Opt. 2003, 42, 5365-5381. [CrossRef] [PubMed]

25. Voss, K.J.; Chapin, A. Upwelling radiance distribution camera system, NURADS. Opt. Express 2005, 13, 4250-4262. [CrossRef] [PubMed]

26. Morel, A.; Gentili, B.; Claustre, H.; Babin, M.; Bricaud, A.; Ras, J.; Tieche, F. Optical properties of the "clearest" natural waters. Limnol. Oceanogr. 2007, 52, 217-229. [CrossRef]

27. Antoine, D.; d'Ortenzio, F.; Hooker, S.B.; Bécu, G.; Gentili, B.; Tailliez, D.; Scott, A.J. Assessment of uncertainty in the ocean reflectance determined by three satellite ocean color sensors (MERIS, SeaWiFS and MODIS-A) at an offshore site in the Mediterranean Sea (BOUSSOLE project). J. Geophys. Res. 2008, 113, C07013. [CrossRef]

28. Chang, G.C.; Dickey, T.D. Interdisciplinary sampling strategies for detection and characterization of harmful algal blooms. In Real-Time Observation Systems for Ecosystem Dynamics and Harmful Algal Blooms; Babin, M., Roesler, C.S., Cullen, J.J., Eds.; UNESCO: Paris, France, 2008; pp. 43-84. 
29. Lewis, M.R.; Wei, J.; Van Dommelen, R.; Voss, K.J. Quantitative estimation of the underwater radiance distribution. J. Geophys. Res. 2011, 116, C00H06. [CrossRef]

30. Wei, J.; Dommelen, R.V.; Lewis, M.R.; McLean, S.; Voss, K.J. A new instrument for measuring the high dynamic range radiance distribution in near surface sea water. Opt. Express 2012, 20, 27024-27038. [CrossRef] [PubMed]

31. Antoine, D.; Morel, A.; Leymarie, E.; Houyou, A.; Gentili, B.; Victori, S.; Buis, J.-P.; Buis, N.; Meunier, S.; Canini, M.; et al. Underwater radiance distributions measured with miniaturized multispectral radiance cameras. J. Atmos. Ocean. Technol. 2013, 30, 74-95. [CrossRef]

32. Cunningham, A.; McKee, D. Measurement of hyperspectral underwater light fields. In Subsea Optics and Imaging; Watson, J.E., Zielinski, O., Eds.; Woodhead Publishing: Philadelphia, PA, USA, 2013; pp. 83-97.

33. Lewis, M.R. Measurement of apparent optical properties for diagonosis of harmful algal blooms. In Real-Time Observation Systems for Ecosystem Dynamics and Harmful Algal Blooms; Babin, M., Roesler, C.S., Cullen, J.J., Eds.; UNESCO: Paris, France, 2008; pp. 207-236.

34. Zibordi, G.; Voss, K.J. In situ optical radiometry in the visible and near infrared. In Optical Radiometry for Ocean Climate Measurements; Zibordi, G., Donlon, C.J., Parr, A.C., Eds.; Academic Press: San Diego, CA, USA, 2014; pp. 248-305.

35. Smith, R.C.; Baker, K.S. The bio-optical state of ocean waters and remote sensing. Limnol. Oceanogr. 1978, 23, 247-259. [CrossRef]

36. Siegel, D.A.; Dickey, T.D. Observations of the vertical structure of the diffuse attenuation coefficient spectrum. Deep-Sea Res. 1987, 34, 547-563. [CrossRef]

37. Dirks, R.W.J.; Spitzer, D. On the radiative transfer in the sea, including fluorescence and stratification effects. Limnol. Oceanogr. 1987, 32, 942-953. [CrossRef]

38. Morel, A. Optical modeling of the upper ocean in relation to its biogenous matter content (case I waters). J. Geophys. Res. 1988, 93, 10749-10768. [CrossRef]

39. Morel, A.; Maritorena, S. Bio-optical properties of oceanic waters: A reappraisal. J. Geophys. Res. 2001, 106, 7163-7180. [CrossRef]

40. Zibordi, G.; D'Alimonte, D.; Berthon, J.-F. An evaluation of depth resolution requirements for optical profiling in coastal waters. J. Atmos. Ocean. Technol. 2004, 21, 1059-1073. [CrossRef]

41. Yarbrough, M.A.; Houlihan, T.; Feinholz, M.; Flora, S.; Johnson, B.C.; Kim, Y.S.; Murphy, M.Y.; Ondrusek, M.; Clark, D. Results in coastal waters with high resolution in-situ spectral radiometry: The Marine Optical System ROV. In Coastal Ocean Remote Sensing; Frouin, R.J., Ed.; SPIE Proceedings; SPIE: Bellingham, WA, USA, 2007; Volume 6680, p. 66800I.

42. Antoine, D.; Hooker, S.B.; Bélanger, S.; Matsuoka, A.; Babin, M. Apparent optical properties of the Canadian Beaufort Sea-Part 1: Observational overview and water column relationships. Biogeosciences 2013, 10, 4493-4509. [CrossRef]

43. Lee, Z; Shaoling, S; Stavn, R.H. AOPs are not additive: On the biogeo-optical modeling of the diffuse attenuation coefficient. Front. Mar. Sci. 2018, 5, Article 8. [CrossRef]

44. Pegau, W.S.; Cleveland, J.S.; Doss, W.; Kennedy, C.D.; Maffione, R.A.; Mueller, J.L.; Stone, R.; Trees, C.C.; Weidemann, A.D.; Wells, W.H.; et al. A comparison of methods for the measurement of the absorption coefficient in natural waters. J. Geophys. Res. 1995, 100, 13201-13220. [CrossRef]

45. Preisendorfer, R.W. Application of radiative transfer theory to light measurements in the sea. Int. Union Geod. Geophys. Monogr. Symp. Radiant Energy Sea 1961, 10, 11-30.

46. Preisendorfer, R.W. Hydrologic Optics. Volume I. Introduction; US Department of Commerce, National Oceanic and Atmospheric Administration, Environmental Research Laboratories: Honolulu, HI, USA, 1976.

47. Kirk, J.T. Volume scattering function, average cosines, and the underwater light field. Limnol. Oceanogr. 1991, 36, 455-467. [CrossRef]

48. Gordon, H.R. Modeling and simulating radiative transfer in the ocean . In Ocean Optics; Spinrad, R.W., Carder, K.L., Perry, M.J., Eds.; Oxford University Press: New York, NY, USA, 1994; pp. 3-39.

49. Gershun, A. The light field. J. Math. Phys. 1939, 18, 51-151. [CrossRef]

50. Tyler, J.E.; Richardson, W.H.; Holmes, R.W. Method for obtaining the optical properties of large bodies of water. J. Geophys. Res. 1959, 64, 667-673. [CrossRef]

51. Højerslev, N.K. A spectral light absorption meter for measurements in the sea. Limnol. Oceanogr. 1975, 20, 1024-1034. [CrossRef] 
52. Spitzer, D.; Wernand, M.R. In situ measurements of absorption spectra in the sea. Deep-Sea Res. 1981, 28A, 165-174. [CrossRef]

53. Gordon, H.R. Inverse methods in hydrologic optics. Oceanologia 2002, 44, 9-58.

54. Gordon, H.R.; Brown, O.B.; Jacobs, M.M. Computed relationships between the inherent and apparent optical properties of a flat homogeneous ocean. Appl. Opt. 1975, 14, 417-427. [CrossRef] [PubMed]

55. Kirk, J.T. Monte Carlo study of the nature of the underwater light field in, and of the relationship between optical properties of, turbid yellow waters. Aust. J. Mar. Freshw. Res. 1981, 32, 517-532. [CrossRef]

56. Gordon, H.R. Absorption and scattering estimates from irradiance measurements: Monte Carlo simulations. Limnol. Oceanogr. 1991, 36, 769-777. [CrossRef]

57. Sathyendranath, S.; Platt, T. Angular distribution of the submarine light field: Modification by multiple scattering. Proc. R. Soc. Lond. A 1991, 433, 287-297. [CrossRef]

58. Stramska, M.; Stramski, D.; Mitchell, B.G.; Mobley, C.D. Estimation of the absorption and backscattering coefficients from in-water radiometric measurements. Limnol. Oceanogr. 2000, 45, 628-641. [CrossRef]

59. Loisel, H.; Stramski, D. Estimation of inherent optical properties of natural waters from the irradiance attenuation coefficient and reflectance in the presence of Raman scattering. Appl. Opt. 2000, 39, 3001-3011. [CrossRef] [PubMed]

60. Morel, A.; Gentili, B. Radiation transport within oceanic (case 1) water. J. Geophys. Res. 2004, 109, C06008. [CrossRef]

61. Lewis, M.R.; Cullen, J.J.; Platt, T. Phytoplankton and thermal structure of the ocean: Consequences of nonuniformity in the chlorophyll profile. J. Geophys. Res. 1983, 88, 2565-2570. [CrossRef]

62. Gordon, H.R. Diffuse reflectance of the ocean: Influence of nonuniform phytoplankton pigment profile. Appl. Opt. 1992, 31, 2116-2129. [CrossRef] [PubMed]

63. Stramska, M.; Stramski, D. Effects of a nonuniform vertical profile of chlorophyll concentration on remote-sensing reflectance of the ocean. Appl. Opt. 2005, 44, 1735-1747. [CrossRef] [PubMed]

64. Li, L.; Stramski, D.; Reynolds, R.A. Characterization of the solar light field within the ocean mesopelagic zone based on radiative transfer simulations. Deep Sea Res. Part I 2014, 87, 53-69. [CrossRef]

65. Gordon, H. Remote sensing of optical properties in continuously stratified waters. Appl. Opt. 1978, 17, 1893-1897. [CrossRef] [PubMed]

66. Yang, Q.; Stramski, D.; He, M.-X. Modeling the effects of near-surface plumes of suspended particulate matter on remote-sensing reflectance of coastal waters. Appl. Opt. 2013, 52, 359-374. [CrossRef] [PubMed]

67. Stavn, R.H.; Weidemann, A.D. Optical modeling of clear ocean light fields: Raman scattering effects. Appl. Opt. 1988, 27, 4002-4011. [CrossRef] [PubMed]

68. Marshall, B.R.; Smith, R.C. Raman scattering and in-water ocean optical properties. Appl. Opt. 1990, $29,71-84$. [CrossRef] [PubMed]

69. Kattawar, G.W.; Xu, X. Filling in of Fraunhofer lines in the ocean by Raman scattering. Appl. Opt. 1992, 31, 6491-6500. [CrossRef] [PubMed]

70. Ge, Y.; Gordon, H.R.; Voss, K.J. Simulation of inelastic-scattering contributions to the irradiance field in the ocean: Variation in Fraunhofer line depths. Appl. Opt. 1993, 32, 4028-4036. [CrossRef] [PubMed]

71. Stavn, R.H. Effects of Raman scattering across the visible spectrum in clear ocean water: A Monte Carlo study. Appl. Opt. 1993, 32, 6853-6863. [CrossRef] [PubMed]

72. Hu, C.; Voss, K.J. In situ measurements of Raman scattering in clear ocean water. Appl. Opt. 1997, 36, 6962-6967. [CrossRef] [PubMed]

73. Berwald, J.; Stramski, D.; Mobley, C.D.; Kiefer, D.A. The effect of Raman scattering on the average cosine and the diffuse attenuation coefficient of irradiance in the ocean. Limnol. Oceanogr. 1998, 43, 564-576. [CrossRef]

74. Gordon, H.R. Contribution of Raman scattering to water-leaving radiance: A reexamination. Appl. Opt. 1999, 38, 3166-3174. [CrossRef] [PubMed]

75. Li, L.; Stramski, D.; Reynolds, R.A. Effects of inelastic radiative processes on the determination of water-leaving spectral radiance from extrapolation of underwater near-surface measurements. Appl. Opt. 2016, 55, 7050-7067. [CrossRef] [PubMed]

76. Lavín, M.F.; Marinone, S.G. An overview of the physical oceanography of the Gulf of California. In Nonlinear Processes in Geophysical Fluid Dynamics; Velasco Fuentes, O.U., Sheinbaum, J., Ochoa, J., Eds.; Springer: Dordrecht, The Netherlands, 2003; pp. 173-204. 
77. Lluch-Cota, S.E.; Aragon-Noriega, E.A.; Arreguín-Sánchez, F.; Aurioles-Gamboa, D.; Bautista-Romero, J.J.; Brusca, R.C.; Cervantes-Duarte, R.; Cortés-Altamirano, R.; Del-Monte-Luna, P.; Esquivel-Herrera, A.; et al. The Gulf of California: Review of ecosystem status and sustainability challenges. Prog. Oceanogr. 2007, 73, 1-26. [CrossRef]

78. Ras, J.; Claustre, H.; Uitz, J. Spatial variability of phytoplankton pigment distributions in the Subtropical South Pacific Ocean: Comparison between in situ and predicted data. Biogeosciences 2008, 5, 353-369. [CrossRef]

79. Ritchie, R.J. Universal chlorophyll equations for estimating chlorophylls a, b, c, and d and total chlorophylls in natural assemblages of photosynthetic organisms using acetone, methanol, or ethanol solvents. Photosynthetica 2008, 46, 115-126. [CrossRef]

80. Gordon, H.R. Ship perturbation of irradiance measurements at sea 1: Monte Carlo simulations. Appl. Opt. 1985, 24, 4172-4182. [CrossRef] [PubMed]

81. Waters, K.J.; Smith, R.C.; Lewis, M.R. Avoiding ship-induced light-field perturbation in the determination of oceanic optical properties. Oceanography 1990, 3, 18-21. [CrossRef]

82. Zibordi, G.; Darecki, M. Immersion factors for the RAMSES series of hyper-spectral underwater radiometers. J. Opt. A Pure Appl. Opt. 2006, 8, 252-258. [CrossRef]

83. Stramski, D. Fluctuations of solar irradiance induced by surface waves in the Baltic. Bull. Pol. Acad. Sci. Earth Sci. 1986, 34, 333-344.

84. Darecki, M.; Stramski, D.; Sokólski, M. Measurements of high-frequency light fluctuations induced by sea surface waves with an Underwater Porcupine Radiometer System. J. Geophys. Res. 2011, 116, C00H09. [CrossRef]

85. Sullivan, J.M.; Twardowski, M.S.; Zaneveld, J.R.V.; Moore, C.M.; Barnard, A.H.; Donaghay, P.L.; Rhoades, B. Hyperspectral temperature and salt dependencies of absorption by water and heavy water in the $400-750 \mathrm{~nm}$ spectral range. Appl. Opt. 2006, 45, 5294-5309. [CrossRef] [PubMed]

86. Sokal, R.R.; Rohlf, F.J. Biometry: The Principles and Practice of Statistics in Biological Research, 3rd ed.; W.H. Freeman: New York, NY, USA, 1995.

87. Banse, K. Should we continue to use the $1 \%$ light depth convention for estimating the compensation depth of phytoplankton for another 70 years. Limnol. Oceanogr. Bull. 2004, 13, 49-52. [CrossRef]

88. Sugihara, S.; Kishino, M.; Okami, N. Contribution of Raman scattering to upward irradiance in the sea. J. Oceanogr. Soc. Jpn. 1984, 40, 397-404. [CrossRef]

89. Bristow, M.; Nielsen, D.; Bundy, D.; Furtek, R. Use of water Raman emission to correct airborne laser fluorosensor data for effects of water optical attenuation. Appl. Opt. 1981, 20, 2889-2906. [CrossRef] [PubMed]

90. Hoge, F.E.; Swift, R.N. Airborne simultaneous spectroscopic detection of laser-induced water Raman backscatter and fluorescence from chlorophyll a and other naturally occurring pigments. Appl. Opt. 1981, 20, 3197-3205. [CrossRef] [PubMed]

91. Stramski, D.; Tegowski, J. Effects of intermittent entrainment of air bubbles by breaking wind waves on ocean reflectance and underwater light field. J. Geophys. Res. 2001, 106, 31345-31360. [CrossRef]

92. Bannister, T.T. Model of the mean cosine of underwater radiance and estimation of underwater scalar irradiance. Limnol. Oceanogr. 1992, 37, 773-780. [CrossRef]

93. Berwald, J.; Stramski, D.; Mobley, C.D.; Kiefer, D.A. Influences of absorption and scattering on vertical changes in the average cosine of the underwater light field. Limnol. Oceanogr. 1995, 40, 1347-1357. [CrossRef]

94. Aas, E.; Højerslev, N.K. Analysis of underwater radiance observations: Apparent optical properties and analytic functions describing the angular radiance distribution. J. Geophys. Res. 1999, 104, 8015-8024. [CrossRef]

95. Sathyendranath, S.; Platt, T. Ocean-color model incorporating transspectral processes. Appl. Opt. 1998, 37, 2216-2227. [CrossRef] [PubMed]

96. Nahorniak, J.S.; Abbott, M.R.; Letelier, R.M.; Pegau, W.S. Analysis of a method to estimate chlorophyll-a concentration from irradiance measurements at varying depths. J. Atmos. Ocean. Technol. 2001, 18, $2063-2073$. [CrossRef]

97. Brown, C.A.; Huot, Y.; Purcell, M.J.; Cullen, J.J.; Lewis, M.R. Mapping coastal optical and biogeochemical variability using an autonomous underwater vehicle and a new bio-optical inversion algorithm. Limnol. Oceanogr. Methods 2004, 2, 262-281. [CrossRef] 
98. Xing, X.; Morel, A.; Claustre, H.; d'Ortenzio, F.; Poteau, A. Combined processing and mutual interpretation of radiometry and fluorometry from autonomous profiling Bio-Argo floats: 2 . Colored dissolved organic matter absorption retrieval. J. Geophys. Res. 2012, 117, C04022. [CrossRef]

99. Westberry, T.K.; Boss, E.; Lee, Z. Influence of Raman scattering on ocean color inversion models. Appl. Opt. 2013, 52, 5552-5561. [CrossRef] [PubMed]

100. Liu, C.C.; Carder, K.L.; Miller, R.L.; Ivey, J.E. Fast and accurate model of underwater scalar irradiance. Appl. Opt. 2002, 41, 4962-4974. [CrossRef] [PubMed]

101. Liu, C.C.; Miller, R.L.; Carder, K.L.; Lee, Z.; D’Sa, E.J.; Ivey, J.E. Estimating the underwater light field from remote sensing of ocean color. J. Oceanogr. 2006, 62, 235-248. [CrossRef]

102. Sathyendranath, S.; Platt, T. Computation of aquatic primary production: Extended formalism to include effect of angular and spectral distribution of light. Limnol. Oceanogr. 1989, 34, 188-198. [CrossRef]

103. O'Reilly, J.E.; Maritorena, S.; Mitchell, B.G.; Siegel, D.A.; Carder, K.L.; Garver, S.A.; Kahru, M.; McClain, C. Ocean color chlorophyll algorithms for SeaWiFS. J. Geophys. Res. 1998, 103, 24937-24953. [CrossRef]

104. O’Reilly, J.E.; Maritorena, S.; Siegel, D.A.; O’Brien, M.C.; Hooker, S.B.; Smith, R.; Menzies, D.; Mueller, J.L.; Kahru, M.; Toole, D.; et al. SeaWiFS Postlaunch Calibration and Validation Analyses, Part. 3, NASA/TM-2000-206892; Hooker, S.B., Firestone, E.R., Eds.; NASA Goddard Space Flight Center: Greenbelt, MD, USA, 2000; Volume 11.

105. Smith, R.C.; Baker, K.S. Optical classification of natural waters. Limnol. Oceanogr. 1978, $23,260-267$. [CrossRef]

106. Gordon, H.R.; Morel, A. Remote Assessment of Ocean Color for Interpretation of Satellite Visible Imagery: A Review; Springer: New York, NY, USA, 1983.

107. Smith, R.C.; Baker, K.S. Optical properties of the clearest natural waters (200-800 nm). Appl. Opt. 1981, 20, 177-184. [CrossRef] [PubMed]

108. Frouin, R.; Lingner, D.W.; Gautier, C.; Baker, K.S.; Smith, R.C. A simple analytical formula to compute clear sky total and photosynthetically available solar irradiance at the ocean surface. J. Geophys. Res. 1989, 94, 9731-9742. [CrossRef]

109. Morel, A. Optical properties and radiant energy in the waters of the Guinea dome and the Mauritanian upwelling area in relation to primary production. J. Cons. Int. Explor. Mer 1982, 180, 94-107.

110. Siegel, D.A.; Dickey, T.D. On the parameterization of irradiance for open ocean photoprocesses. J. Geophys. Res. 1987, 92, 14648-14662. [CrossRef]

111. Smith, R.C.; Marra, J.; Perry, M.J.; Baker, K.S.; Swift, E.; Buskey, E.; Kiefer, D.A. Estimation of a photon budget for the upper ocean in the Sargasso Sea. Limnol. Oceanogr. 1989, 34, 1673-1693. [CrossRef]

112. Moore, C.C.; Bruce, E.J.; Pegau, W.S.; Weidemann, A.D. WET Labs ac-9: Field calibration protocol, deployment techniques, data processing, and design improvements. In Ocean Optics XIII; SPIE Proceedings; SPIE: Bellingham, WA, USA, 1997; Volume 2963, pp. 725-731. [CrossRef]

113. Twardowski, M.S.; Sullivan, J.M.; Donaghay, P.L.; Zaneveld, J.R.V. Microscale quantification of the absorption by dissolved and particulate material in coastal waters with an ac-9. J. Atmos. Ocean. Technol. 1999, 16, 691-707. [CrossRef]

114. Röttgers, R.; McKee, D.; Woźniak, S.B. Evaluation of scatter corrections for ac-9 absorption measurements in coastal waters. Methods Oceanogr. 2013, 7, 21-39. [CrossRef]

115. Sathyendranath, S.; Platt, T. The spectral irradiance field at the surface and in the interior of the ocean: A model for applications in oceanography and remote sensing. J. Geophys. Res. 1988, 93, 9270-9280. [CrossRef]

(C) 2018 by the authors. Licensee MDPI, Basel, Switzerland. This article is an open access article distributed under the terms and conditions of the Creative Commons Attribution (CC BY) license (http://creativecommons.org/licenses/by/4.0/). 